\title{
Hidden diversity within a polytypic species: The enig- matic Sceloporus torquatus Wiegmann, 1828 (Reptilia, Squamata, Phrynosomatidae)
}

\section{Taxonomic revision of Sceloporus torquatus}

\author{
Gustavo Campillo-García ${ }^{1,2}$, Oscar Flores-Villela ${ }^{1}$, Brett Oliver Butler ${ }^{1}$, Julián Andrés Velasco \\ Vinasco $^{3}$, Fabiola Ramírez Corona ${ }^{4}$ \\ 1 Museo de Zoología "Alfonso L. Herrera", Facultad de Ciencias, Universidad Nacional Autónoma de México, Av. Ciudad Universitaria 3000 \\ C. P. 04510, Coyoacán, CDMX, México \\ 2 Posgrado en Ciencias Biológicas, Universidad Nacional Autónoma de México, Av. Ciudad Universitaria 3000, C. P. 04510, Coyoacán, CDMX, \\ México \\ 3 Instituto de Ciencias de la Atmósfera y Cambio Climático, Universidad Nacional Autónoma de México, Av. Ciudad Universitaria 3000, C. P. \\ 04510, Coyoacán, CDMX, México \\ 4 Taller de biogeografia y sistemática, Facultad de Ciencias, Universidad Nacional Autónoma de México, Av. Ciudad Universitaria 3000, C. P. \\ 04510, Coyoacán, CDMX, México
}

http://zoobank.org/0160231E-5792-46FE-9F29-C1995472B6F1

Corresponding author: Oscar Flores-Villela (ofvq@unam.mx)

Academic editor Uwe Fritz | Received 23 July $2021 \quad$ Accepted 9 November $2021 \quad$ Published 3 December 2021

Citation: Campillo-García G, Flores-Villela O, Butler BO, Velasco Vinasco JA, Ramírez Corona F (2021) Hidden diversity within a polytypic species: The enigmatic Sceloporus torquatus Wiegmann, 1828 (Reptilia, Squamata, Phrynosomatidae). Vertebrate Zoology 71 781-798. https://doi. org/10.3897/vz.71.e71995

\begin{abstract}
The spiny lizard genus Sceloporus was described by Wiegmann in 1828, with $S$. torquatus posteriorly designated as the type species. The taxonomic history of $S$. torquatus is complicated, as it has been confused with other taxa by numerous authors. Many modern systematics works have been published on Sceloporus, but none have included all five recognized $S$. torquatus subspecies: S. t. torquatus, S. t. melanogaster, $S$. t. binocularis, S. t. mikeprestoni, and S. t. madrensis. Additionally, there is previous evidence for at least one unnamed taxon. The present study is the first taxonomic revision of the enigmatic $S$. torquatus based on molecular phylogenies using combined molecular data from 12S, ND4 and RAG1 genes, and Maximum Likelihood and Bayesian inference phylogenetic methods. This work includes the most extensive sampling across the entire distribution, as well as divergence time estimates and environmental niche modelling, which combined offer a spatio-temporal framework for understanding the evolution of the species. Additionally, a series of morphological characters are analyzed to identify significant differences between lineages consistently recovered in the molecular phylogenies. Using this integrative approach, evidence is presented for eight lineages within the $S$. torquatus complex, five of which correspond to previously recognized subspecies and three represent unnamed taxa masked by morphological conservatism. Finally, to maintain taxonomic stability a lectotype and paralectoype are designated for $S$. torquatus, and certain taxonomic changes are suggested in order to reflect the phylogenetic relationships within the S. torquatus complex.
\end{abstract}

\section{Keywords}

Collared spiny lizard, Ecological Niche Modelling, integrative taxonomy

Copyright Gustavo Campillo-Garcia et al. This is an open access article distributed under the terms of the Creative Commons Attribution License (CC BY 4.0), which permits unrestricted use, distribution, and reproduction in any medium, provided the original author and source are credited. 


\section{Introduction}

If we were to choose a representative genus of North American reptiles, Sceloporus Wiegmann, 1828 would certainly be a good candidate, as it is one of the most diverse and conspicuous. Sceloporus is a genus of Phrynosomatid lizards distributed from southern Canada to western Panama with over 100 species (Sites et al. 1992; Köhler and Heimes 2002; Bell et al. 2003; Wiens et al. 2010; Uetz et al. 2020), although the greatest diversity is found in Mexico (Flores-Villela and García-Vázquez 2014), where new species are still being described (Castañeda-Gaytán and Díaz-Cárdenas in Díaz-Cárdenas et al. 2017).

Sceloporus has proven to be an ideal group to study systematics (Sites et al. 1992), and consequently the molecular systematics of the genus has been very dynamic and fundamental for the understanding of phylogenetic relationships as well as in the practice of species delimitation (Leaché and Reeder 2002; Wiens and Penkrot 2002; Leaché and Mulcahy 2007; Leaché 2010; Wiens et al. 2010; Bryson et al. 2012; Leaché et al. 2013; Grummer et al. 2015; Díaz-Cárdenas et al. 2017, 2019; Lambert et al. 2019).

Despite the amount of published data on the group, controversy persists about the recognition of species and the phylogenetic relationships at species group level in the genus Sceloporus. In addition, sampling of some species and subspecies is still incomplete (Leaché 2010; Wiens et al. 2010), as is the case for Sceloporus torquatus Wiegmann, 1828 (Martínez-Méndez and Méndez-De la Cruz 2007; Martínez-Méndez et al. 2019).

Sceloporus torquatus is the type species of the genus (Smith 1938) and is currently recognized as a polytypic species comprising five subspecies that display minimal morphological differentiation, essentially distinguishable by color pattern, number of ventral scales, body size and arm length (Olson 1990): S. t. torquatus, S. t. melanogaster Cope, 1885, S. t. binocularis Dunn, 1936, S. $t$. mikeprestoni Smith and Álvarez, 1974, and S. t. madrensis Olson, 1986. As a whole, S. torquatus is widespread in central and northern Mexico (Fig. 1), where they are found from arid and semi-arid zones of the Altiplano Mexicano into temperate highlands of the peripheral Faja Volcánica Transmexicana, Sierra Madre Occidental, and Sierra Madre Oriental. Zones of sympatry have been suggested in central Mexico, in which interbreeding presumably occurs between $S$. $t$. torquatus and both $S$. t. melanogaster and S. t. madrensis (Smith 1938; Webb 1967; Olson 1990, 1991). Among the five recognized subspecies, only S. t. madrensis has a disjunct distribution, whos's northern and southern populations are divided by $\sim 175 \mathrm{~km}$ and isolated on a mountainous range of eastern Mexico (Olson 1991).

Previous works included sampling of three of the five recognized subspecies as well as molecular evidence for an unnamed taxon from western Mexico related to S. torquatus (Martínez-Méndez and Méndez-De la Cruz 2007; Martínez-Méndez et al. 2019). However, phylo- genetic relationships and taxonomic statuses of all five subspecies have not been reassessed with an integrative approach.

Herein we perform the first taxonomic revision of the five subspecies of $S$. torquatus based on molecular phylogenies inferred by Bayesian and Maximum Likelihood methods, using mitochondrial and nuclear DNA data. To set up a spatio-temporal framework for interpreting the evolution of this endemic Mexican lizard group, we also calculate genetic distances, estimate divergence times, and perform ecological niche modelling (ENM) for the lineages consistently recovered in the inferred phylogenies. Additionally, we analyze a series of morphometric and scutellation characteristics, using both Principal Component Analysis (PCA) and non-Metric Multidimensional Scaling (nMDS), in order to identify significant differences between lineages.

With this revision we aim to solve one of the oldest taxonomic problems in Mexican herpetology, while providing useful data that may be applied for species conservation efforts.

\section{Taxonomic background}

Since its original description, the taxonomy of $S$. torquatus has been problematic (Smith 1938), largely due to it being confused with other similar species such as Sceloporus cyanogenys Cope, 1885 (Baird 1859; Yarrow 1882), Sceloporus mucronatus Cope, 1885 (Olson 1990), Sceloporus poinsettii Baird and Girard, 1852 (Yarrow 1882), Sceloporus serrifer Cope, 1866 (Martin 1952), and Sceloporus spinosus Wiegmann, 1828 (Cope 1885). Some of these taxa have since been relegated to synonymy or reassigned to subspecific categories. Therefore, to address the taxonomic problems associated with $S$. torquatus, it is necessary to briefly review its taxonomic history:

Originally, the genus Sceloporus was erected by Wiegmann (1828) to include the first six Mexican species of spiny lizards, of which $S$. torquatus is the type species (Smith 1938). However, Wiegmann never designated type specimens for the taxa he described, and it was Taylor (1969) who listed a series of four specimens (Zoologisches Museum Berlin, ZMB 628-631) from "Mexico" as $S$. torquatus syntypes (Fig. 2).

A year after Wiegmann (1828) described the first species of Sceloporus, Peale and Green described Agama torquata Peale and Green, 1829 (holotype: Academy of Natural Sciences of Philadelphia, ANSP 8499) based on a single specimen from "Temascaltepec, about eighty miles SW of the city of Mexico."

Later, Wiegmann (1834) expanded the description of $S$. torquatus and distinguished the varieties " $\alpha$ " and " $\beta$ ", essentially by coloration patterns and shape of the nuchal 


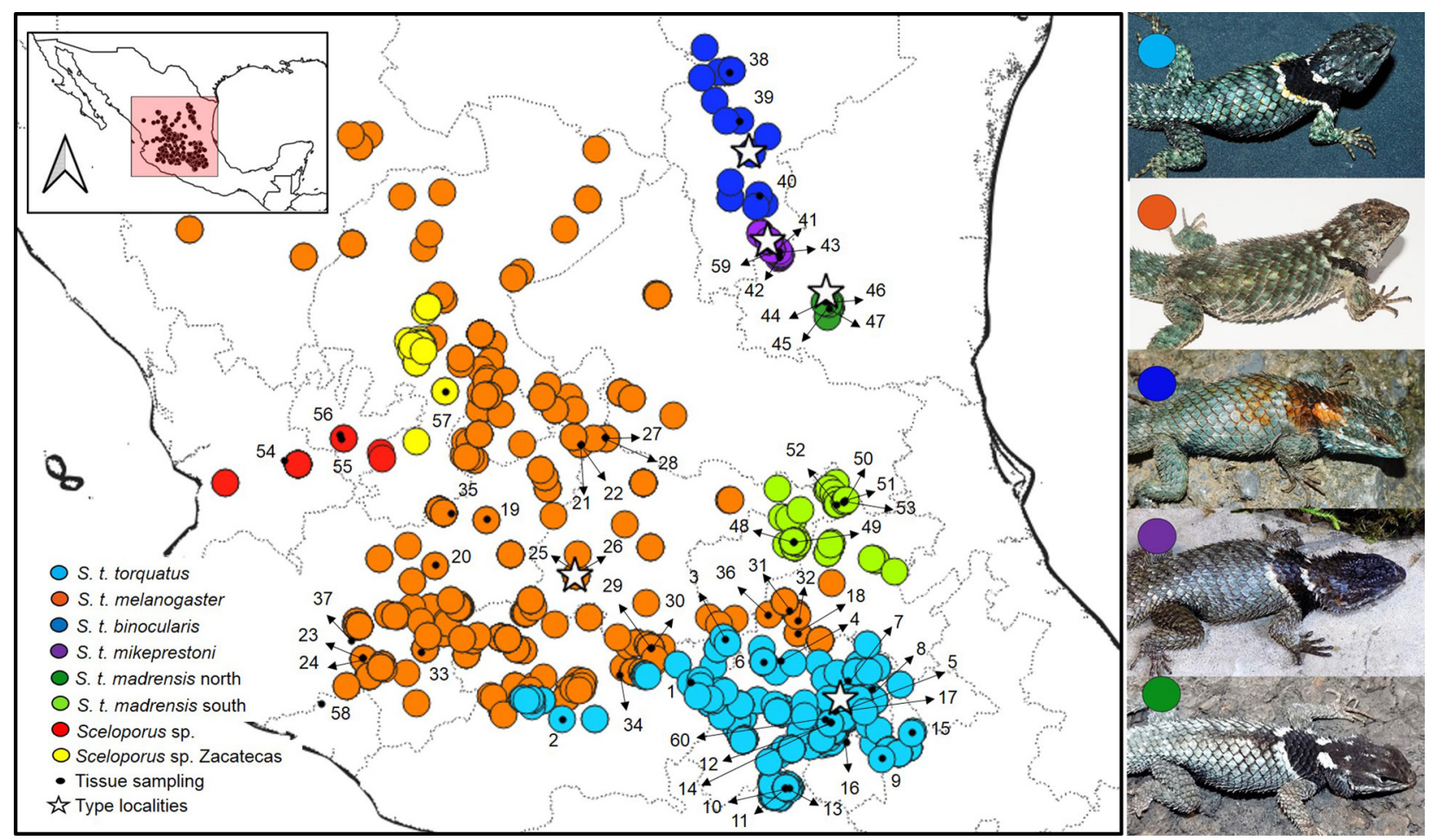

Figure 1. Geographic distribution of Sceloporus torquatus ssp. based on measured and examined specimens. Numbers are specified in supplementary file 2: Tissue sampling and GenBank accession numbers.

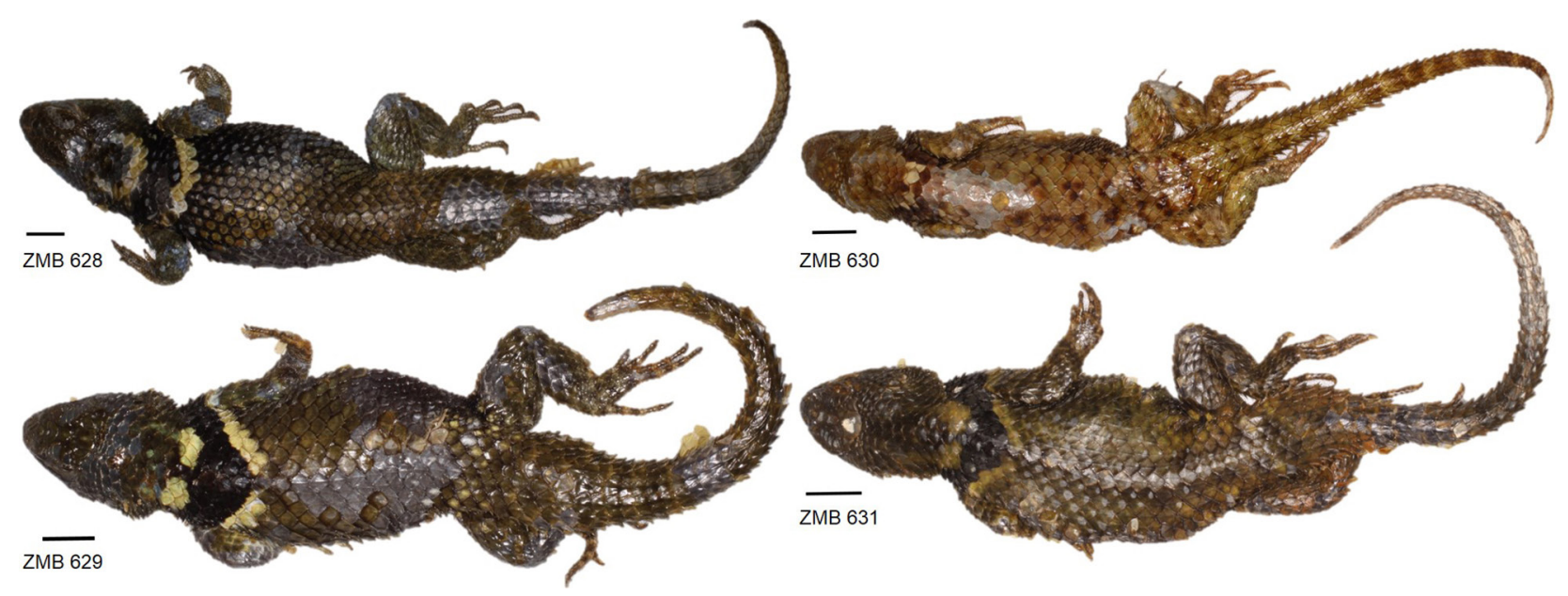

Figure 2. Syntypes of Sceloporus torquatus, Zoologisches Museum Berlin, now Museum für Naturkunde Berlin, (ZMB) 628-630, collected by Ferdinand Deppe and Alexander von Sack in Mexico (circa 1825). ZMB 628, § adult; ZMB 629, ô adult; ZMB 630, † adult; ZMB 631, ô adult. For all cases scale bar $20 \mathrm{~mm}$. Photographs courtesy of F. Tillack.

collar. He also synonymized $A$. torquata with $S$. torquatus "Var. $\alpha$ ", and suggested that the " $\beta$ " variety could be a hybrid between $S$. torquatus and $S$. spinosus.

Cope (1885) reaffirmed synonymy of $A$. torquata with $S$. torquatus and described Sceloporus ferrariperezi Cope, 1885 (Cotypes: United States National Museum, USNM 9874, 9876, 9878, 9880, and 9895 now Museum of Comparative Zoology, MCZ 46922), as well as Sceloporus melanogaster Cope, 1885 (holotype: USNM 9877) from specimens sent by Dugès (1887). That same year, Boulenger (1885) considered S. ferrariperezi and $S$. melanogaster to be varieties of $S$. torquatus.
Almost 50 years later, Smith (1936) recognized $S$. torquatus and $S$. ferrariperezi as valid, although in a subsequent review Smith (1938) synonymized $S$. ferrariperezi with $S$. torquatus and reassigned $S$. melanogaster as a subspecies of $S$. torquatus, but clarified that, according to the taxonomic rules at the time, $S$. ferrariperezi had to replace $S$. torquatus because the latter was a homonym of Stellio torquatus (= Tropidurus torquatus) Wied-Neuwied, 1820. That same year, Sceloporus binocularis Dunn, 1936 was described (holotype: ANSP 20032; paratypes: ANSP 20019, 20020) with specimens from "Trail from Pablillo to Alamar, Nuevo Leon." Two years later, 
Table 1. Number of examined and measured specimens. Measured specimens are those specimens measured for morphometrics and/or scutellation. Examined specimens are those specimens examined directly in collections or by photos to confirm identify and contribute to delimiting the geographic distribution patterns of the $S$. torquatus complex, but were not measured for morphometrics and/or scutellation. Other specimens include those specimens redetermined as different species.

\begin{tabular}{|l|c|c|c|}
\hline \multirow{2}{*}{ Taxa } & \multirow{2}{*}{ Examined } & \multicolumn{2}{|c|}{ Measured } \\
\cline { 3 - 4 } & & Morphometrics & Scutellation \\
\hline S.t. torquatus & 206 & 249 & 279 \\
\hline S. t. melanogaster & 273 & 226 & 13 \\
\hline S. t. binocularis & 3 & 5 & 21 \\
\hline S. t. mikeprestoni & 1 & 21 & 27 \\
\hline S. . madrensis north & 1 & 28 & 31 \\
\hline S. t. madrensis south & 23 & 10 & 15 \\
\hline Sceloporus sp. & 6 & 25 & 17 \\
\hline Sceloporus sp. Zacatecas & 9 & 6 & 0 \\
\hline Type material & 21 & 0 & 0 \\
\hline Other specimens & 32 & & \\
\hline
\end{tabular}

Smith (1939) applied the nomenclatural change from $S$. torquatus to $S$. ferrariperezi, and recognized the species as polytypic containing $S . f$. ferrariperezi, $S$. f. melanogaster, and $S$. f. binocularis. This nomenclatural change was subsequently reversed by Smith and Taylor (1950), reestablishing the validity of $S$. torquatus.

Several years later, another subspecies, Sceloporus torquatus mikeprestoni Smith and Álvarez, 1974 (holotype: MCZ R115679; paratypes: Escuela Nacional de Ciencias Biológicas, ENCB 5756-5763) was described from specimens collected in "Marcela, Tamaulipas".

Finally, the subspecies Sceloporus torquatus madrensis Olson 1986 (holotype: Texas Cooperative Wildlife Collection, TCWC 62433; paratypes: University of Michigan Museum of Zoology, UMMZ 101395, 101400 , 101401, 110743, Rupert Earl Olson, REO 1184-1186, 1193, 5569) was described based on specimens from "about Rancho del Cielo, 7 km. NW Gomez Farias, Tamaulipas."

\section{Methods}

\section{Museum specimens}

In total we measured 684 specimens (Table 1) deposited at the Colección Nacional de Anfibios y Reptiles (CNAR), ENCB and Museo de Zoología Alfonso L. Herrera (MZFC). Additionally, to verify some historical records and for comparison and objective reference, we requested photographs of museum specimens including type material deposited in another 19 collections (See supplementary file 1: Museum specimens).

We georeferenced all localities using GoogleEarth Pro v.7.3.3.7699 and digitized topographic maps available in the digital library of the Instituto Nacional de Estadística y Geografía (INEGI, https://www.inegi.org.mx/app/ mapas). In the field we used a Garmin etrex30 GPS with WGS84 datum to record collection localities.

\section{Genetic sampling}

For genetic analyses, we obtained 56 tissue samples from the MZFC collection and field work, that include individuals collected in close proximity to the type localities of all five recognized subspecies of $S$. torquatus, as well as the undescribed Sceloporus sp. from western Mexico sensu Martínez-Méndez and Méndez-De la Cruz (2007). Samples of Sceloporus bulleri Boulenger, 1895, S. mucronatus Cope, 1885, and Sceloporus grammicus Wiegmann, 1828 were also included (Fig. 1; Supplementary file 2: Tissue sampling and GenBank accession numbers). We chose the mitochondrial 12S and ND4 loci, and the nuclear RAG1 locus for genetic analyses, as these regions have successfully been utilized to delimit species Sceloporus species in similar studies (Wiens and Penkrot 2002; Martínez-Méndez et al. 2012; Díaz-Cárdenas et al. 2017).

\section{Laboratory protocols}

To perform DNA extractions, we used the Qiagen ${ }^{\mathrm{TM}}$ DNeasy Blood \& Tissue Kit ${ }^{\mathrm{TM}}$ following the manufacturer's protocol.

We amplified fragments of the $12 \mathrm{~S}$ and ND4 mtDNA regions, and RAG1 of nDNA by means of polymerase chain reaction (PCR) under the following standardized conditions: $1 \mu \mathrm{L}$ DNA extraction, $9.45 \mu \mathrm{L} \mathrm{dH}_{2} \mathrm{O}, 3 \mu \mathrm{L} 5 \mathrm{X}$ MyTaq ${ }^{\text {TM }}$ Reaction Buffer, $0.5 \mu \mathrm{L}$ Primer F $[10 \mu \mathrm{M}], 0.5 \mu \mathrm{L}$ Primer R $(10 \mu \mathrm{M})$ and $0.15 \mu \mathrm{L} \mathrm{MyTaq}{ }^{\mathrm{TM}} \operatorname{Bioline}^{\mathrm{TM}}(5 \mathrm{U})$. PCRs were carried out in a Multigene Optimax LabNet ${ }^{\mathrm{TM}}$ thermocycler with the following annealing temperatures for each molecular marker: $45^{\circ} \mathrm{C}, 12 \mathrm{~S} ; 54^{\circ} \mathrm{C}$, ND4; and $50^{\circ} \mathrm{C}, \mathrm{RAG} 1$. The oligonucleotides sequences used (Table 2) were taken from Kocher et al. (1989), Forstner et al. (1995) and Wiens et al. (2010).

We used the sequencing service of the Laboratorio Nacional de Biodiversidad (LANABIO) at the Instituto de Biología (IBUNAM), which uses the BigDye Terminator v.3.1 Applied Biosystems kit and a final purification with Sephadex G-50 before analyzing cycle sequencing prod- 
Table 2. Oligonucleotides used for gene amplification.

\begin{tabular}{|l|l|l|}
\hline \multirow{2}{*}{ Gene } & Name: Sequence (5'-3') & Source \\
\hline \multirow{2}{*}{ NDS } & L1091rRNA12S: CAAACTGGATTAGATACCCCACTAT & \multirow{2}{*}{ Kocher et al. 1989 } \\
\cline { 2 - 4 } & H1478rRNA12S: AGGGTGACGGGCGGTGTGT & \multirow{2}{*}{ Forstner et al. 1995 } \\
\cline { 2 - 3 } \multirow{2}{*}{ RAG1 } & ND4: TGACTACCAAAAGCTCATGTAGAAGC & \multirow{2}{*}{ Wiens et al. 2010 } \\
\cline { 2 - 4 } & JRAG1f2: CAAAGTRAGATCACTTGAGAAGC & \\
\cline { 2 - 4 } & JRAG1r3: ACTTGYAGCTTGAGTTCTCTCTTAGRCG & \\
\hline
\end{tabular}

uct on an Applied Biosystems 3730 xL DNA Analyzer Sequencer.

\section{Sequence alignment}

Once sequences were obtained, we used MUSCLE (Edgar 2004) implemented in MEGA-X v.10.0.5 (Kumar et al. 2018) to pair contigs and align sequences. Subsequently, we reviewed alignments by eye, and eliminated small regions of the sequences that contained polymorphic sites that were difficult to align.

\section{Phylogenetic analysis}

We constructed two molecular data matrices - the first one exclusively with the mtDNA data (12S + ND4) and the second with the combined data from $\mathrm{mtDNA}+\mathrm{nDNA}$ $(12 \mathrm{~S}+\mathrm{ND} 4+\mathrm{RAG1})$. We also included sequence data generated in previous works (Martínez-Méndez and Méndez-De la Cruz 2007; Leaché and Mulcahy 2007). For accession numbers of sequences used see supplementary file 2: Tissues sampling. To identify the optimal partitions in both datasets, as well as the best nucleotide substitution model for each partition, we used PartitionFinder2 (Lanfear et al. 2016) through the CIPRES Science Gateway v.3.3 interface (Miller et al. 2010), with potential partitions divided by codon position for coding regions.

To infer the phylogenetic relationships of $S$. torquatus ssp. we performed both Bayesian inference and ML analyses with both mitochondrial and combined datasets, using MrBayes v.3.2.7a (Ronquist et al. 2012) and RaxML-HPC2 (Stamatakis 2014) through the CIPRES Science Gateway v.3.3 interface (Miller et al. 2010). In each Bayesian analysis we specified the following parameters: mcmcp ngen $=60000000$, burninfrac $=0.25$, printfreq $=6000$, and samplefreq $=6000$; while in each Maximum Likelihood analysis we specified the GTRGAMMA model of nucleotide substitution and 1000 bootstrap iterations. We included Sceloporus grammicus as the sister group to the entire torquatus species group, $S$. mucronatus as a member of the torquatus species group, as well as Sceloporus bulleri as the sister species of $S$. torquatus (Martínez-Méndez and Méndez-De la Cruz 2007).

We used Tracer v.1.7.1. (Rambaut et al. 2018) to check the Markov chains (MCMC) convergence implemented in MrBayes, and FigTree v1.4.4 (Rambaut 2018) to visualize the resulting phylogenetic trees.

\section{Genetic distances}

Genetic distances were calculated using the concatenated matrix of mtDNA data (12S + ND4). Using MEGA X v.10.0.5 (Kumar et al. 2018), we constructed a Neighbor-Joining tree with 1000 bootstrap iterations and the Kimura2-parameter model (Kimura 1980) to subsequently calculate the genetic distances between groups defined by lineages recovered in the phylogenetic analyses under the same parameters. We designed $S$. bulleri as the external group because it is the sister species of $S$. torquatus.

\section{Divergence times}

We estimated divergence times between lineages using BEAST v2.5.1 (Bouckaert et al. 2019) under a Yule tree model. We inferred models of substitution and rate heterogeneity using bModelTest (Bouckaert and Drummond 2017) for four partitions: 12S, the ND4 coding region, the noncoding tNRA region of ND4, and RAG1. We estimated two separate uncorrelated relaxed clock models for the combined mitochondrial loci and the nuclear RAG1 loci, respectively. A secondary calibration was used to calibrate the node corresponding to the most recent common ancestor between the torquatus species group and S. grammicus. A uniform prior between 12.9 and 18 mya was used for this node, as this range encompasses the estimated divergence date for these taxa in two previous studies on the group (Wiens et al. 2013; Leaché et al. 2016), and has been used in recent divergence estimations for the torquatus species group (Lambert et al. 2019). Three independent runs of $40000000 \mathrm{MCMC}$ generations were run, sampling every 4000 generations. We assessed convergence in Tracer v.1.7.1 (Rambaut et al. 2018), where we compared replicate runs for similar parameter values and then combined them using LogCombiner after discarding the first $10 \%$ of trees of each run as burn-in. We used TreeAnnotator to create a maximum clade credibility tree using the median ancestor height and visualized the resulting tree in FigTree v1.4.4 (Rambaut 2018).

\section{Ecological Niche Modelling (ENM)}

We performed a series of statistical analyses to evaluate the multivariate niche overlap between lineages in the environmental spaces. We used the "PCA-env" approach (Broennimann et al. 2012) implemented in the ecospat $\mathrm{R}$ 
packages (Di Cola et al. 2017). This approach calculates niche overlap using the Schoener's $D$ metric from the first two principal component analysis (PCA) including climate information from the respective lineage occurrence distributions and their background from the calibration area (see below). A smoothed occurrence density was estimated for each lineage using a kernel density function, and this was used to calculate niche overlap. We implemented randomization tests to assess niche similarity for each lineage pair (Di Cola et al. 2017). Here we test whether lineage pairs are more similar than expected based on their background environments (i.e., species are occupying niches that are more similar given the environmental availability in the region). As we are interested in testing a scenario of ecological niche conservatism, testing whether lineages in the $S$. torquatus complex were more similar than expected by the background conditions is the most appropriate null hypothesis here. We used 100 random replications for these tests. We used an ensemble approach given the high uncertainty in model algorithm selection on transferability under past climate change scenarios. We selected a set of bioclimatic variables for model fit based on collinearity, which was calculated using the Variance Inflation Factor (VIF; Marquaridt 1970). The VIF was calculated for the 19 bioclimatic variables from WorldClim using the vifcor $\mathrm{R}$ function from the $u s d m$ package (Naimi et al. 2014). Afterward, we selected the following variables for model fit: bio4, bio9, bio15, bio18 and bio19. We evaluated our models by creating pseudo-absences and with data-splitting methods. First, we randomly partitioned the presence data into two sets for calibration $(70 \%)$ and validation $(30 \%)$. For each dataset (calibration and validation), we generated a set of pseudo-absences using the ecospat.rand.pseudoabsences function from ecospat R package (Di Cola et al. 2017). The number of pseudo-absences for calibration was 10 times the number of training presences and for validation was 100 times the number of testing presences (i.e., 800 pseudo-absences). Pseudo-absences were created randomly across the entire calibration area or accessible area ( $\mathrm{M}$ area; Soberón and Peterson 2005) with a minimum distance of at least $5 \mathrm{~km}$ with respect to presence records. This area represents the hypothetical historical suitable area (HSA) where lineages recovered in our phylogenetic analysis evolved through time. We adopted this validation approach to maximize the number of pseudo-absences in both cross-validation splits and external validation. We used eight model algorithms available in the sdm R package (Naimi and Aráujo 2016), including MaxEnt (Maximum Entropy), MARS (Multivariate Adaptive Regression Splines), GBM (Gradient Boosting Machine), RF (Random Forest), CART (Classification and Regression Trees), SVM (Support Vector Machines), GLM (Generalized Linear Model) and GAM (Generalized Additive Model). Models were trained using 5-folds of cross-validation and 10 bootstrapping replications for a total of 50 replications per algorithm. For each individual model, we evaluated geographical predictive accuracy using the true skill statistic (TSS) and omission rate (Allouche et al. 2006; Fielding and Bell 1997). Finally, we generated a consensus ensemble model weighting for those models maximizing TSS values. This model identifies areas where those models with the highest predictive capacity tend to agree with the environmental conditions for successful population establishment (i.e., habitat suitability distribution).

Then, ensembles were transferred to past climate change scenarios from the paleoclimatic database PaleoClim (Brown et al. 2018) to generate past suitable conditions. This database contains bioclimatic information for 11 time horizons since the last Meghalayan until the mid-Miocene. The time periods are as follows (in parentheses the estimated time period): Meghalayan (4.20.3 kya), Northgrippian (8.3-4.2 kya), Greenlandian (11.7-8.3 kya), Younger Dryas Stadial (12.9-11.7 kya), Bølling-Allerød (14.7-12.9 kya), Heinrich Stadial (17.014.7 kya), Last Glacial Maximum (LGM; 21 kya), Inter-Glacial (LIG; 121 kya), the Marine Isotope Stage 19 in the Pleistocene (MIS19; 787 kya), mid-Pliocene Warm ( 3.2 mya) and the Marine Isotope Stable in the Late Pliocene (M2; 3.3 mya). These periods include several abrupt global climate change events (Thornalley et al. 2010; 2011; 2013; Brown et al. 2018). We stacked individual models and then estimated the median of suitability values across the region to identify areas where the optimal niche conditions coincided for the majority of lineages as the historical stable areas (HSA).

\section{Morphological analysis}

We tested whether those lineages recovered by molecular phylogenetic analyses exhibit morphological differences through PCA and nMDS methods using morphometric and scutellation characters.

We followed Olson (1990) and Smith (1939) for morphometric and scutellation terminology. All measurements and counts were made by the same person (GCG) using a Mitutoyo 500-196-30 digital caliper (with an accuracy of $\pm 0.1 \mathrm{~mm})$, a $3 \times$ magnifier, and a Zeiss $5 \times$ stereomicroscope.

We measured 576 individuals exceeding 70mm SVL snout-vent length as $S$. torquatus reaches sexual maturity at this body size (Guillette and Méndez-De la Cruz 1993; Feria Ortiz et al. 2001). We built a data matrix with 10 morphometric traits (See supplementary file 3: Morphometric measurements). Additionally, a data matrix with 18 scutellation characters (See supplementary file 4: Scutellation counts) was built from 638 adult and juvenile specimens, as these traits are not body size dependent.

We removed the effect of body size on morphometric variables following Velasco and Herrel (2007) where each variable was $\log 10$-transformed and regressed against snout-vent length (log10-transformed). The residuals of all variables and the snout-vent length ( $\log 10$-transformed) were used in a PCA. Then, we performed a Multivariate Analysis of Variance (MANOVA) with the scores obtained from the principal components (PC) to test for significant differences $(p<0.05)$ between means of the variances of the lineages compared. 
Table 3. Partitions and substitution models used.

\begin{tabular}{|c|c|c|c|}
\hline \multirow{2}{*}{ Data } & \multirow{2}{*}{ Partitions } & \multicolumn{2}{|l|}{ Models } \\
\hline & & Bayesian & ML \\
\hline \multirow{3}{*}{$12 \mathrm{~S}+\mathrm{ND} 4$} & Subset1 $=1-351354-983 \backslash 3984-1070$ & \multirow{4}{*}{$\mathrm{GTR}+\mathrm{I}+\Gamma$} & \multirow{5}{*}{ GTRGAMMA } \\
\hline & Subset2 $=352-983 \backslash 3$ & & \\
\hline & Subset3 $=353-983 \backslash 3$ & & \\
\hline \multirow{2}{*}{$\begin{array}{l}12 \mathrm{~S}+\mathrm{ND} 4+ \\
\text { RAG1 }\end{array}$} & 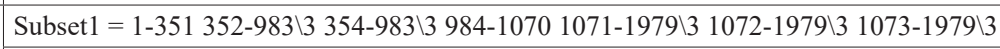 & & \\
\hline & Subset2 $=353-983 \backslash 3$ & $\mathrm{GTR}+\Gamma$ & \\
\hline
\end{tabular}
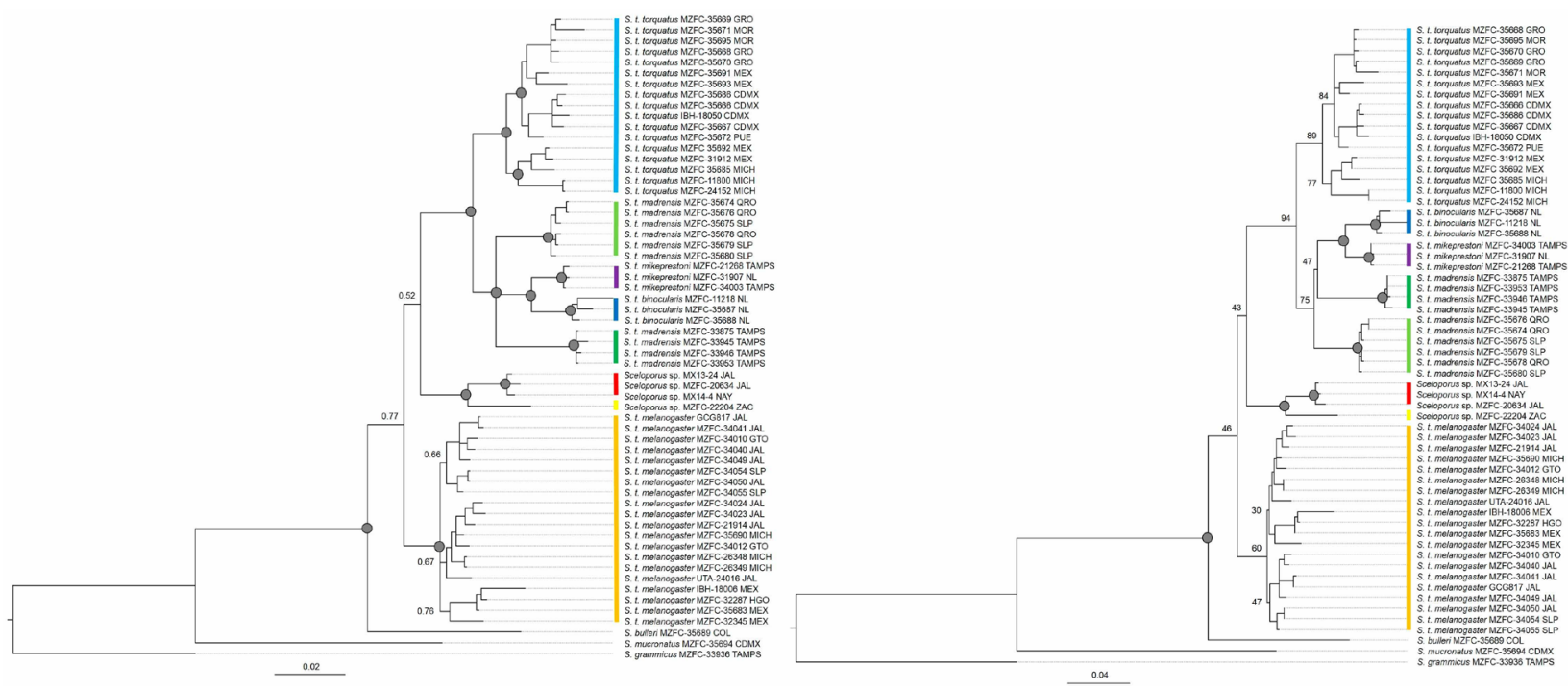

Figure 3. Mitochondrial genes tree with support values, obtained by MrBayes (left) and RAxML (right). Posterior Probability values (PP) and Bootstrap values (BS) are displayed at nodes, with values $\geq 0.95$ designated with grey dots.

Alternatively, with the scutellation data matrix we implemented a non-Metric Multidimensional Scaling (nMDS) analysis with the Manhattan coefficient to calculate total differences of the measured variables between individuals of each recovered lineage.

We carried out these statistical analyzes with the tools provided in PAST v.4.01 (Hammer et al. 2001).

\section{Results}

\section{Sceloporus torquatus syntypes}

We discovered that more than one species is represented in the type series of $S$. torquatus (Fig. 2). Specifically, the specimen ZMB 628 has divided supraocular scales, 32 dorsal scales, 43 ventral scales, and blue coloration on the belly, throat, and both sides of the head; furthermore, dorsal scales are bordered with black, and light borders of the dark nuchal collar are complete. These characters led us to re-determine this specimen as Sceloporus aureolus Smith, 1942.

Additionally, we re-determined the specimen ZMB 630 , a syntype of $S$. torquatus, as $S$. $t$. melanogaster by having undivided supraocular scales, 30 dorsal scales, 41 ventral scales, diffuse dark nuchal collar interrupted by dorsolateral light bands or marks, as well as a series of dark irregular spots that fade over the base of the tail.

Finally, we found that specimen ENCB 5756, a paratype of S. t. mikeprestoni, actually pertains to Sceloporus minor Cope, 1885. This specimen has divided supraocular scales, 36 dorsal scales, 40 scales around the body, and 44 ventral scales.

\section{Molecular data}

We obtained 170 sequences from the 12S (321-351 bp), ND4 + adjacent tRNA (553-719 bp), and RAG1 (909 bp) regions. The mitochondrial data matrix contains 60 samples, $1070 \mathrm{bp}, 770$ conserved sites, 300 variable sites, and 196 parsimony informative sites, while the combined data matrix contains 50 individuals, 1979 bp, with 1639 conserved sites, 350 variable sites, and 205 parsimony informative sites.

The optimal partitioning schemes of the mitochondrial and combined data sets, as well as the best substitution model for each partition, are shown in Table 3.

\section{Phylogenetic analyses}

Mitochondrial gene trees resulting from the Bayesian and ML analyses maintain a similar topology (Fig. 3). 
Table 4. Genetic distances between taxa, calculated using the Kimura 2-parameters model for the combined mitochondrial data.

\begin{tabular}{|c|c|c|c|c|c|c|c|c|}
\hline Taxa & 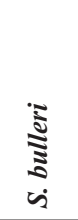 & 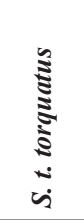 & 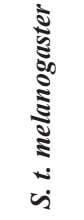 & 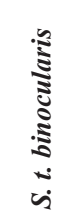 & 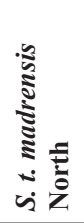 & 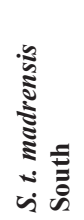 & 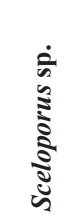 & 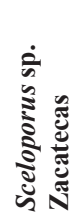 \\
\hline \multicolumn{9}{|l|}{ S. bulleri } \\
\hline S. t. torquatus & 0.074 & & & & & & & \\
\hline S.t. melanogaster & 0.069 & 0.054 & & & & & & \\
\hline S. t. binocularis & 0.083 & 0.045 & 0.058 & & & & & \\
\hline S. t. mikeprestoni & 0.084 & 0.041 & 0.059 & 0.025 & & & & \\
\hline S. t. madrensis north & 0.082 & 0.051 & 0.055 & 0.046 & 0.043 & & & \\
\hline S.t. madrensis south & 0.085 & 0.042 & 0.059 & 0.041 & 0.039 & 0.045 & & \\
\hline Sceloporus sp. & 0.072 & 0.057 & 0.044 & 0.062 & 0.062 & 0.064 & 0.066 & \\
\hline Sceloporus sp. Zacatecas & 0.071 & 0.062 & 0.059 & 0.067 & 0.063 & 0.063 & 0.062 & 0.032 \\
\hline
\end{tabular}
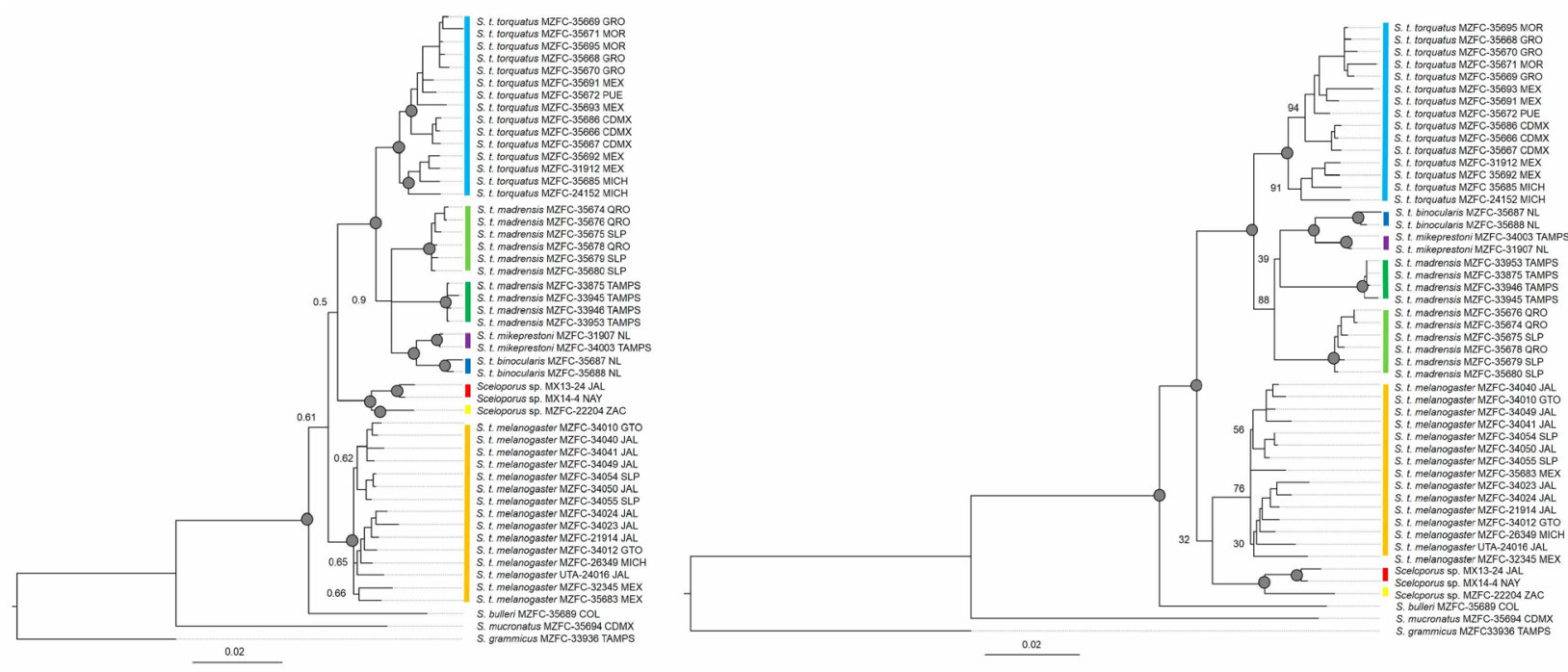

Figure 4. Combined mitochondrial and nuclear genes trees with support values, obtained by MrBayes (left) and RAxML (right). Posterior Probability values (PP) and Bootstrap values (BS) are displayed at nodes, with values $\geq 0.95$ designated with grey dots.

We can identify eight different lineages comprising the $S$. torquatus complex: S. t. torquatus (Posterior Probability, $\mathrm{PP}=1$; Bootstrap, $\mathrm{BS}=89)$, S. t. melanogaster $(\mathrm{PP}=0.99$; $\mathrm{BS}=60), S$. t. binocularis $(\mathrm{PP}=1 ; \mathrm{BS}=100)$, S. t. mikeprestoni $(\mathrm{PP}=1 ; \mathrm{BS}=100), S$. t. madrensis north $(\mathrm{PP}=1$; $\mathrm{BS}=100)$, S. . madrensis south $(\mathrm{PP}=1, \mathrm{BS}=97)$, Sceloporus sp. $(\mathrm{PP}=1, \mathrm{BS}=100)$ and Sceloporus sp. Zacatecas ( $\mathrm{PP}=1, \mathrm{BS}=97)$. The $S$. torquatus complex was found to be monophyletic with respect to the included outgroup taxa, although with low support $(\mathrm{PP}=0.77 ; \mathrm{BS}=46)$.

In both mitochondrial trees, $S$. $t$. torquatus, $S$. $t$. binocularis, $S$. t. mikeprestoni, $S$. $t$. madrensis north, and $S$. $t$. madrensis south forms a clade sister to the clade including Sceloporus sp. and Sceloporus sp. Zacatecas.

Combined mitochondrial and nuclear data phylogenies (Fig. 4) recovered the same eight lineages: $S$. t. torquatus $(\mathrm{PP}=1 ; \mathrm{BS}=97)$, S. t. melanogaster $(\mathrm{PP}=0.97 ; \mathrm{BS}=32), S$. t. binocularis $(\mathrm{PP}=1 ; \mathrm{BS}=100)$, S. t. mikeprestoni $(\mathrm{PP}=1$; $\mathrm{BS}=100), S . t$. madrensis north $(\mathrm{PP}=1 ; \mathrm{BS}=100), S . t$. madrensis south $(\mathrm{PP}=1, \mathrm{BS}=100)$, Sceloporus $\mathrm{sp} .(\mathrm{PP}=1$,
$\mathrm{BS}=100)$ and Sceloporus sp. Zacatecas $(\mathrm{PP}=1, \mathrm{BS}=97)$. In the ML phylogeny, Sceloporus sp. and Sceloporus sp. Zacatecas form the sister clade to $S$. $t$. melanogaster.

We consistently recovered $S$. bulleri and S. mucronatus as the sister species of the $S$. torquatus complex, while $S$. grammicus is sister to all of them.

\section{Genetic distances}

The genetic distance between $S$. bulleri and any member of the $S$. torquatus complex ranges from 0.069-0.085. The genetic distance between $S$. $t$. torquatus and $S$. $t$. melanogaster is 0.054 , between $S$. $t$. binocularis and $S$. t. mikeprestoni is 0.025 , between $S$. $t$. madrensis north and $S$. $t$. madrensis south is 0.045 , and that between Sceloporus sp. and Sceloporus sp. Zacatecas is 0.032 (Table 4). 
Table 5. Schroener's similarity index (Schoener's D).

\begin{tabular}{|c|c|c|c|c|c|c|c|c|}
\hline sp. $1 /$ sp. 2 & $\begin{array}{c}5 \\
5 \\
5 \\
5 \\
5 \\
\vdots \\
\vdots \\
\dot{5}\end{array}$ & 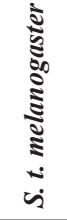 & 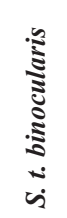 & 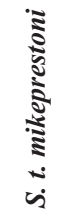 & 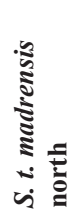 & 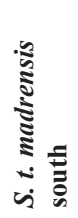 & 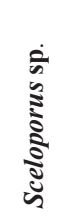 & 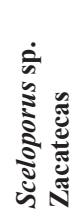 \\
\hline \multicolumn{9}{|l|}{ S. t. torquatus } \\
\hline S. t. melanogaster & 0.18 & & & & & & & \\
\hline S. t. binocularis & 0.10 & 0.44 & & & & & & \\
\hline S. t. mikeprestoni & 0.05 & 0.02 & 0.10 & & & & & \\
\hline S. t. madrensis north & 0.01 & 0.04 & 0.01 & 0.00 & & & & \\
\hline S. t. madrensis south & 0.29 & 0.35 & 0.12 & 0.21 & 0.01 & & & \\
\hline Sceloporus sp. & 0.06 & 0.18 & 0.10 & 0.01 & 0.08 & 0.08 & & \\
\hline Sceloporus sp. Zacatecas & 0.02 & 0.13 & 0.11 & 0.00 & 0.00 & 0.00 & 0.00 & \\
\hline
\end{tabular}

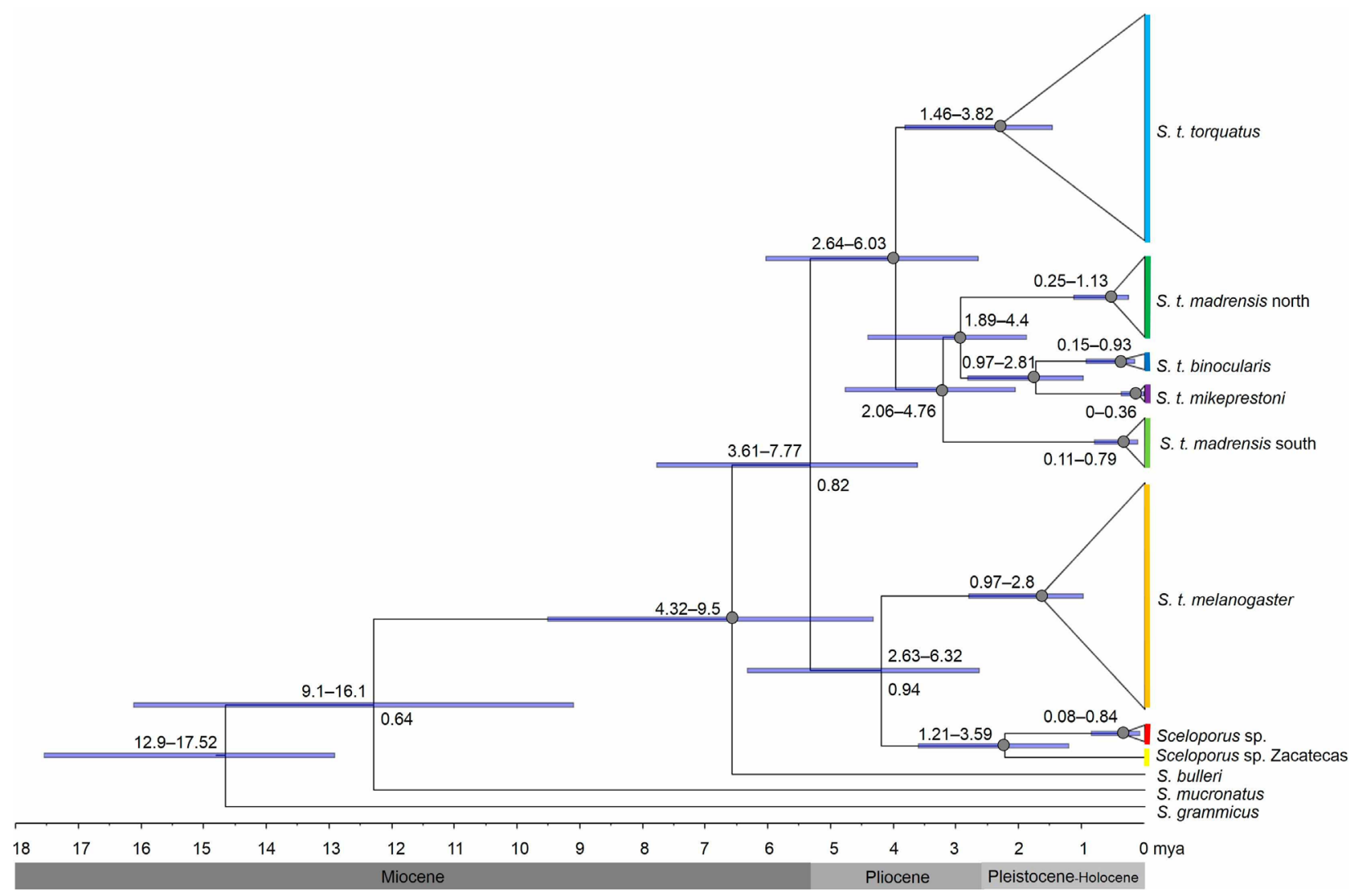

Figure 5. Time-calibrated phylogeny estimated in BEAST2. Posterior Probability values (PP) are displayed at nodes, with values $\geq 0.95$ designated with grey dots. Node age (height), given in millions of years ago (mya), are also displayed at nodes.

\section{Divergence times}

The BEAST time-tree recovered a similar topology and support values to the RAxML and MrBayes trees (Fig. 5). The crown age for the $S$. torquatus complex is $\sim 5.51$ mya (3.61-7.77, 95\% HPD). The split between $S$. $t$. melanogaster and the two lineages from the Sierra Madre Occidental, Sceloporus sp. and Sceloporus sp. Zacatecas, dates to $\sim 4.33$ mya (2.63-6.32, 95\% HPD). The divergence between $S$. $t$. torquatus and the clade including the four lineages from the Sierra Madre Oriental is $\sim 4.12$ mya $(2.64-6.03,95 \%$ HPD). The four lineages from the Sierra Madre Oriental, S. t. madrensis north, $S$. t. madrensis sur, S. t. binocularis, and S. t. mikeprestoni, are recovered as monophyletic with good support and a crown age of $\sim 3.31$ mya (2.06-4.76, 95\% HPD); relative splitting of the two S. t. madrensis lineages is uncertain, given the low internal posterior probability value within this subclade. The timing of these divergences from the binocularis subclade (S. t. binocularis $+S$. t. mikeprestoni) is recovered between 1.89-4.4 mya, and the most recent common ancestor between $S$. $t$. binocularis and $S$. t. mikeprestoni lineages is recovered at $\sim 1.81$ mya $(0.97-$ 2.81, 95\% HPD). 
S. t. torquatus

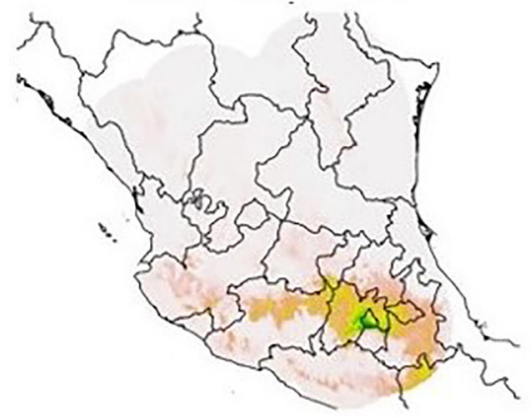

S. t. binocularis

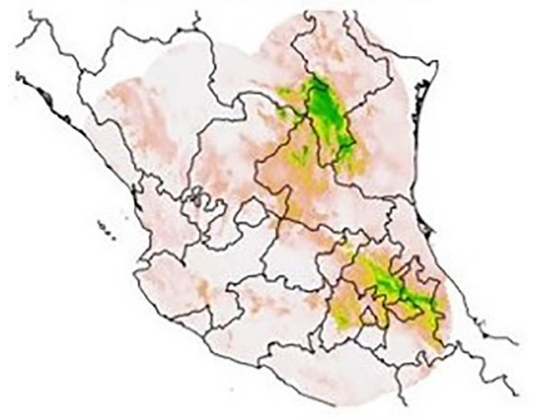

S. t. madrensis north

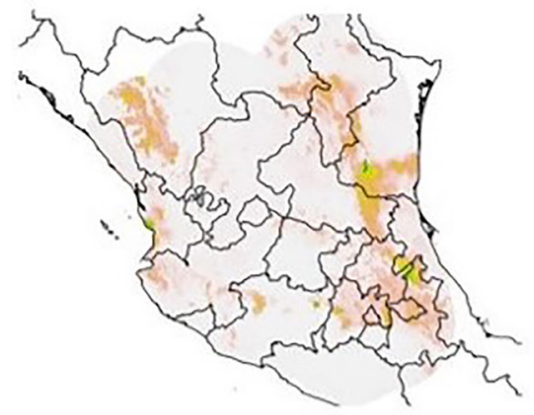

Sceloporus sp.

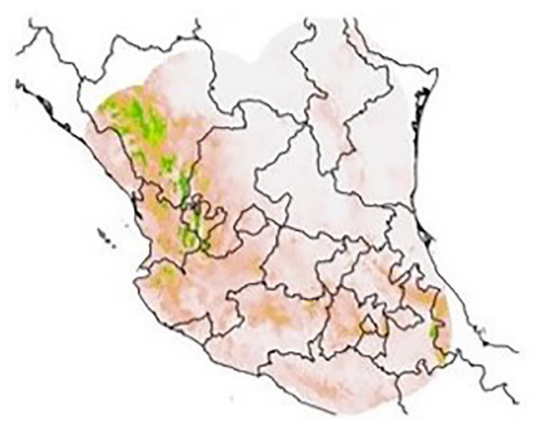

Figure 6. Potential distribution of the S. torquatus complex.

\section{ENM}

In general, there are no similarities in ecological niches of each lineage within the $S$. torquatus complex (Table 5). Comparison between $S$. $t$. melanogaster and $S$. $t$. binocularis shows the highest niche similarity (Schoener's $D=0.44$ ), although their respective $p$-values in the ran-

\section{S. t. melanogaster}
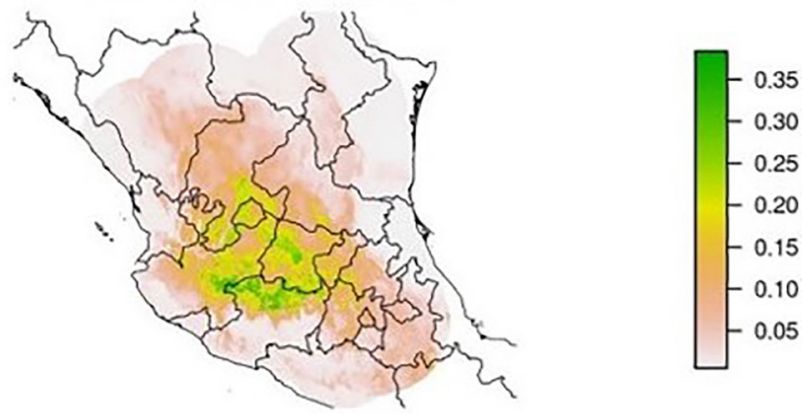

\section{S. t. mikeprestoni}
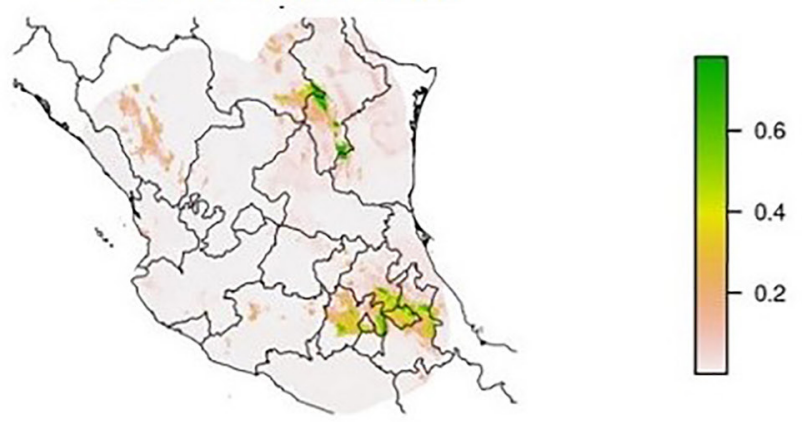

\section{S. t. madrensis south}
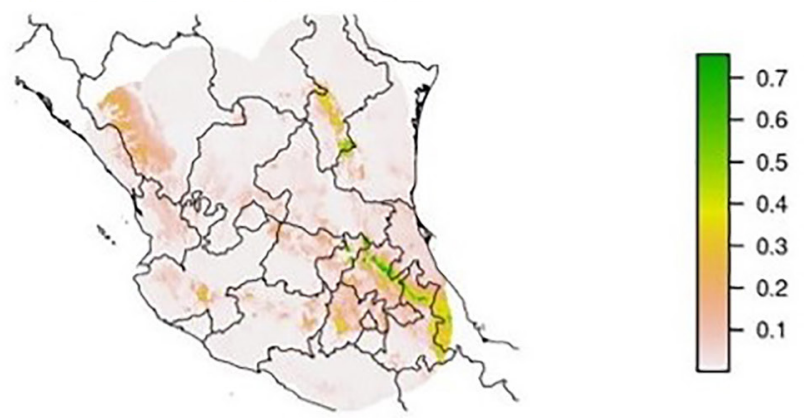

\section{Sceloporus sp. Zacatecas}
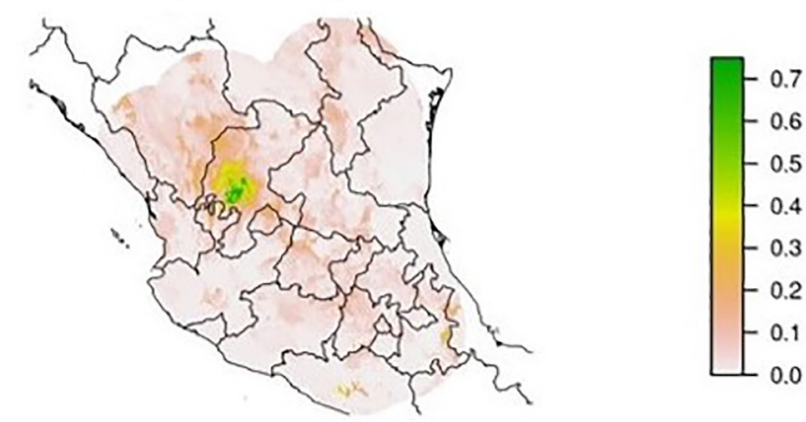

domization test are discrepant ( $p=0.01, p=0.09$; Table 6), and therefore this similarity must be taken with reservations.

Potential distribution models (Fig. 6) illuminate some interesting patterns. For example, $S$. $t$. torquatus has a greater affinity with existing climatic conditions of central and southern Mexico. Given the suitability values 


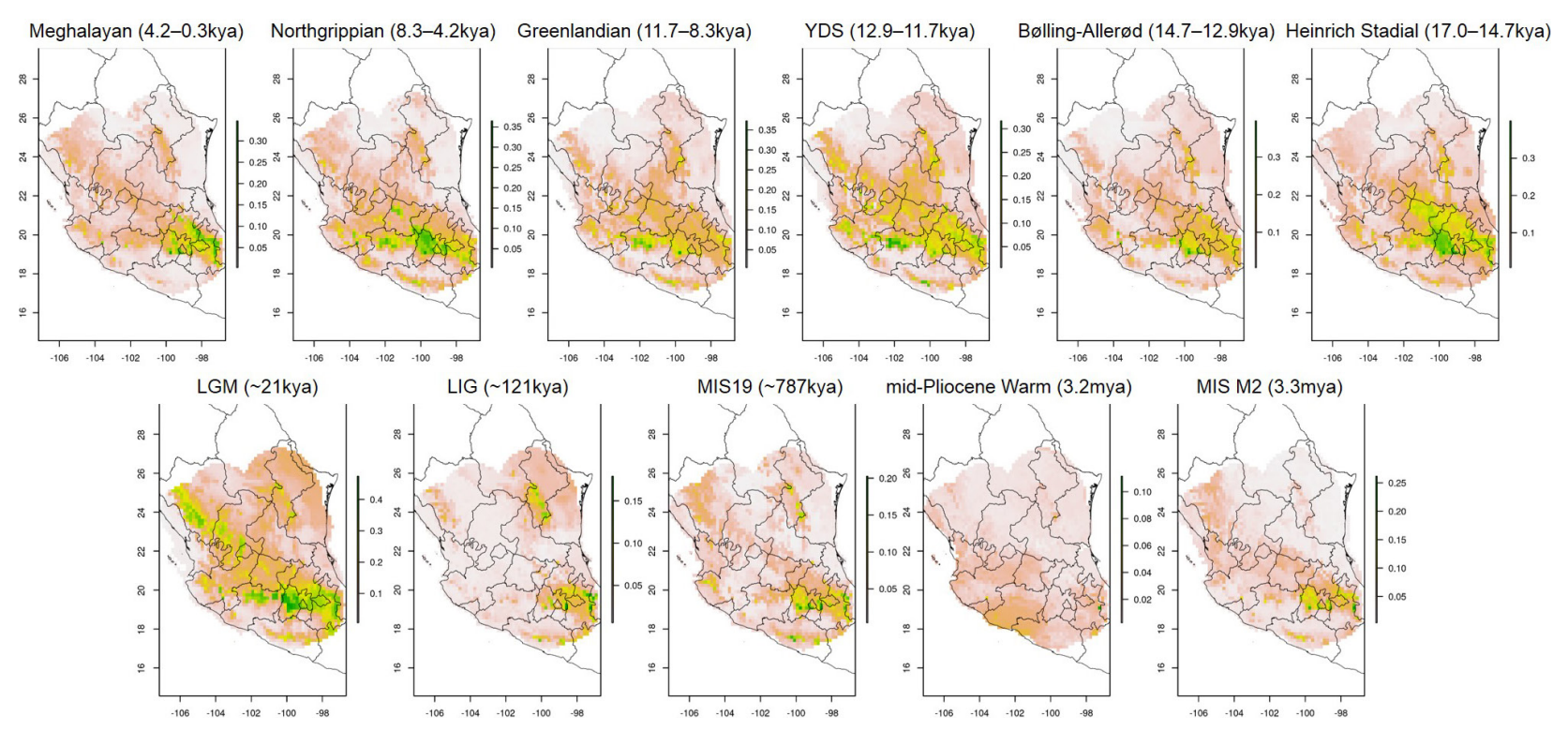

Figure 7. Historical Suitable Areas (HSA) modeled through 11 past climatic scenarios. Green areas indicate higher suitability values.

observed in each model, there seems to be reciprocity between the potential areas of $S$. $t$. binocularis, $S$. $t$. mikeprestoni, and S. t. madrensis north, which together inhabit northeastern Mexico, with respect to the potential area of $S$. $t$. madrensis south which is distributed in central eastern Mexico.

According to models projected into the past, the HSA have been very dynamic as they have expanded and contracted consecutively since the late Pliocene, but have remained associated with the main mountainous regions of central and northern Mexico. Between the mid-Pliocene Warm period ( $\sim 3.2$ mya) and MIS19 ( 787 kya) another HSA appears in Northeast Mexico. Through the different temporal scenarios, except for the mid-Pliocene Warm, an extensive HSA has been maintained in central Mexico (Fig. 7).

\section{Morphology}

A summary of the descriptive statistics for each taxa is shown in supplementary file 5: Geographic distribution, morphometrics and scutellation of the S. torquatus complex.

We performed a PCA and nMDS analyses to contrast the morphology of the $S$. torquatus complex members. There is not clear segregation of the analyzed datasets (Figs 8-9).

In the PCA (Fig. 8), the two first PCs explain $70.8 \%$ of the total variance, and the MANOVA performed with the scores of all ten PCs yielded Wilks $\lambda=0.4175, F=7.541$, $p<0.05$. The scores, eigenvalues, and percentage of the explained variance are shown in the Supplementary file 6: PCA statistics.

The nMDS analysis (Fig. 9) yielded the following values: Stress value $=1.572$; Coefficients of determination $\left(R^{2}\right)$ : Axis $1=0.101$, Axis $2=0.07448$.

\section{Discussion}

\section{Taxonomy}

According to the International Code of Zoological Nomenclature (ICZN; The International Trust for Zoological Nomenclature 1999) the fixation of a type specimen serves as an objective reference for the application of the taxonomic name it carries (Art. 61.1), and such objectivity is hierarchically continuous from the species level to the family level (Art. 61.1.2). Now, if in the original description of a nominal taxon a specimen or specimens bearing the name was not designated, it is possible that such a designation was made later by the figure of the first reviewer (Arts. 24.2.1). In this context, Taylor (1969) served as the first reviewer designating four syntypes for $S$. torquatus. The results we present here, show that the specimens ZMB 628 and ZMB 630 belong to distinct taxonomic species other than $S$. torquatus, thus causing instability in the application of the species name, and therefore warranting a lectotype to be designated from the syntypes (ICZN Arts. 70.3, 74.1). For this purpose, we designate as the lectotype for the name Sceloporus torquatus Wiegmann, 1828 the specimen ZMB 629, and as the paralectotype the specimen ZMB 631. We base the designation of the lectotype on its similarity to the specimen illustrated in Wiegmann (1834; tab. VII, fig. 1), according to ICZN Art.72.4.1.1.

In the other case, misidentification of the S. t. mikeprestoni paratype ENCB 5756 in the original description (Smith and Álvarez 1974) does not exclude it from the type series of this nominal taxon (ICZN Art.72.4.2). 


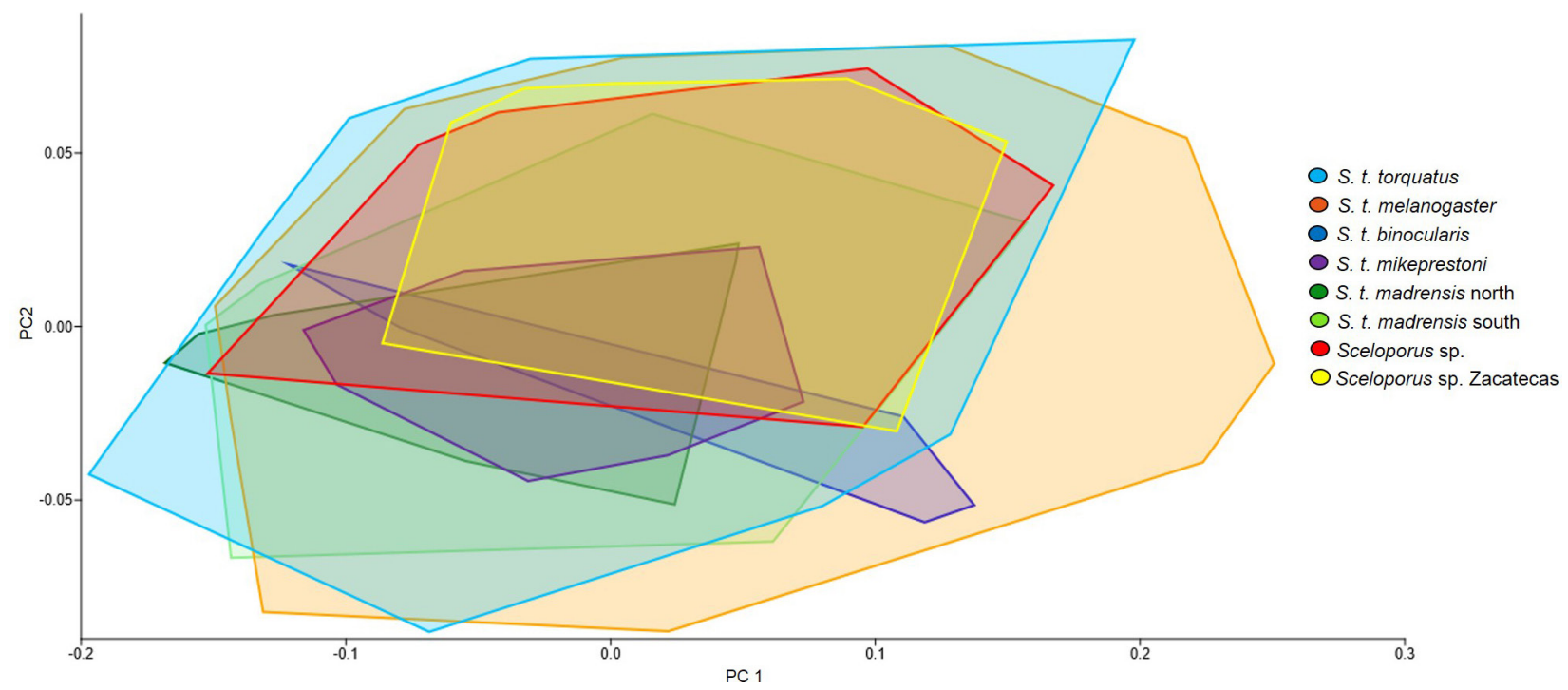

Figure 8. PCA analysis.

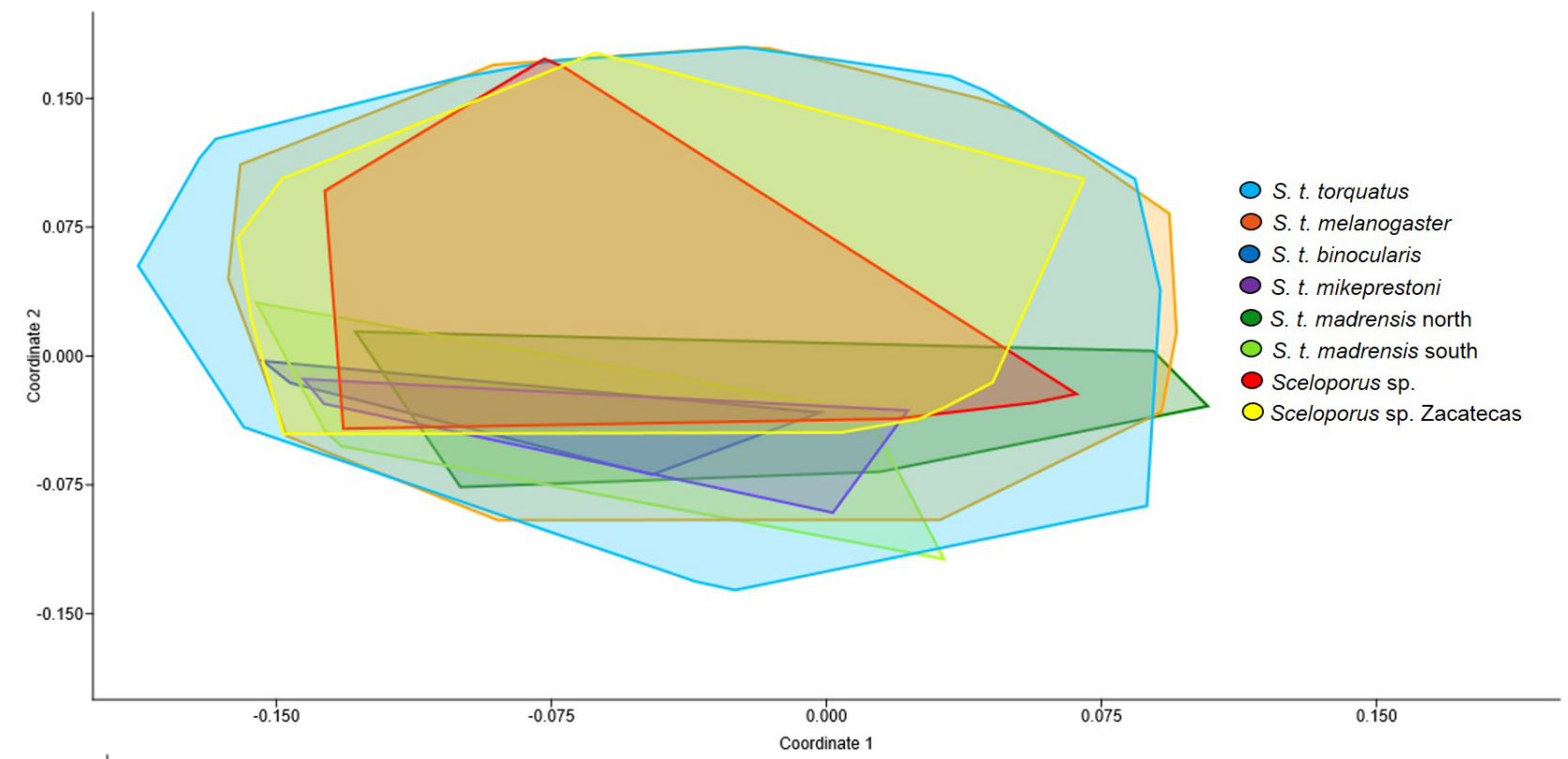

$2.25 \mathrm{E}+05-$

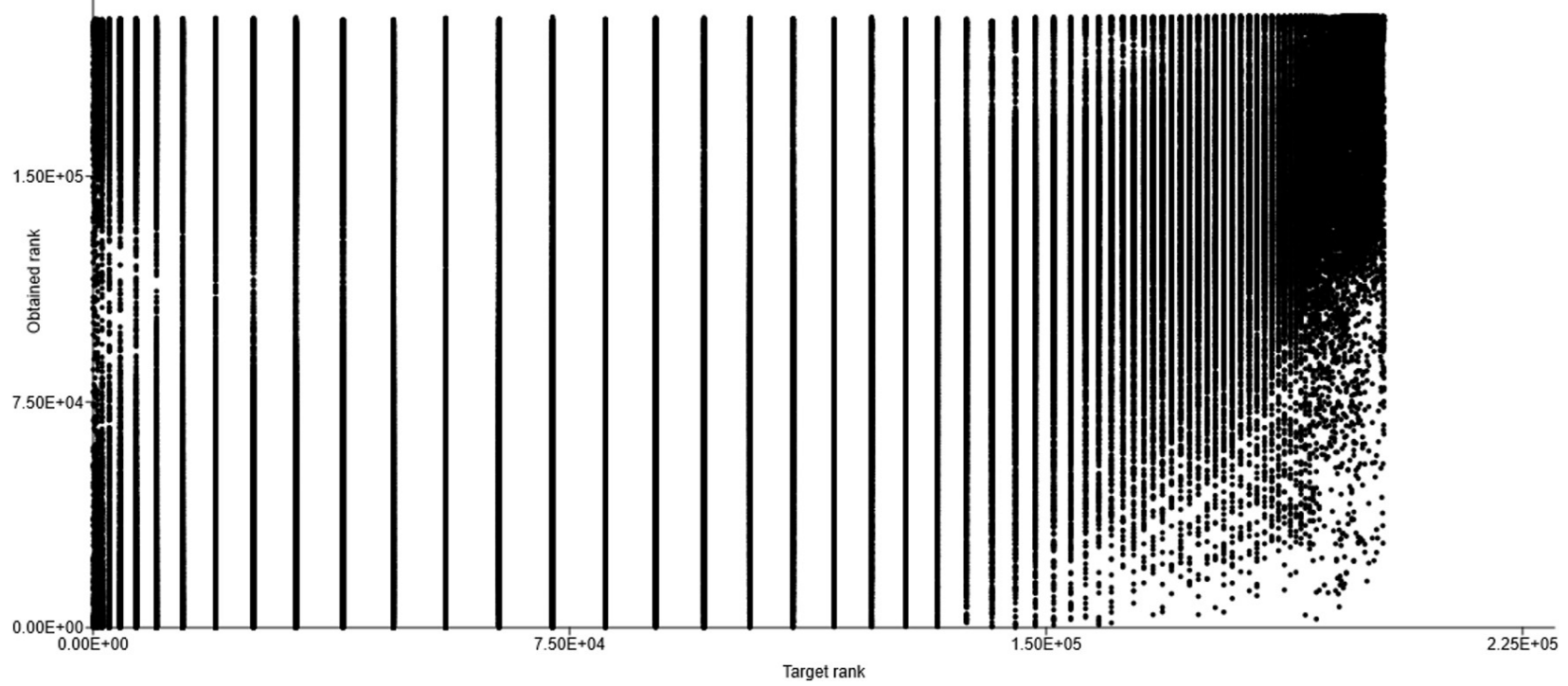

Figure 9. nMDS analysis. 


\section{Integrative systematics of the S. tor- quatus complex}

This study includes genetic data from S. t. mikeprestoni and $S$. $t$. madrensis for the first time ever, as well as the most extensive sampling throughout the distribution of the $S$. torquatus complex, to accomplish the most complete molecular phylogeny of this emblematic group of phrynosomatid lizards to date. The $S$. torquatus complex is a monophyletic group composed of eight independent lineages, five of which represent recognized subspecies, while the remaining three represent unnamed taxa that are awaiting descriptions (Flores-Villela et al. in prep.).

There is evidence to recognize the southern populations of $S$. $t$. madrensis as an independent lineage, previously confused with $S$. t melanogaster and $S$. $t$. madrensis (Smith 1939; Olson 1991). Therefore, there is no zone of sympatry between the southern populations of $S$. $t$. madrensis and S. t. torquatus, as Olson (1991) argued.

In addition, we confirm the existence of another cryptic species from western Mexico suggested by Martínez-Méndez and Méndez-De la Cruz (2007) and Martínez-Méndez et al. (2019). In our research, the lineages Sceloporus sp. and Sceloporus sp. Zacatecas are more closely related to $S$. $t$. melanogaster given the smaller genetic distances between them and their geographical proximity (Figs 1, 5; Table 4).

Additional tissue samples from the northernmost populations of $S$. $t$. melanogaster could help elucidate phylogenetic relationships within the $S$. torquatus complex as a sister taxon of Sceloporus spp. from Nayarit, Jalisco and Zacatecas, and could also solve phylogenetic relationships within the lineage $S$. $t$. melanogaster. Future samplings along the contact zone of $S$. $t$. torquatus and $S$. t. melanogaster in central Mexico would be useful to determine the extent of gene flow, and to investigate mechanisms of reproductive isolation, especially since behavior and coloration are known to be related to conspecific recognition and reproductive success in Sceloporus (Hunsaker 1962; Jiménez-Arcos et al. 2017).

At the end of the Neogene, tectonic and volcanic activity gave rise to the main mountain systems of Mexico, promoting vicariant events in numerous taxa (Morafka 1977; Bryson et al. 2012). Our estimation of divergence times shows that the current phylogeographic structure of the $S$. torquatus complex coincides with this period. Pleistocene climate changes may have led to the diversification of numerous taxa (Bryson et al. 2011, 2012; Leaché et al. 2013; Díaz-Cárdenas et al. 2019), to which we include the most recently diverged lineages within the S. torquatus complex, S. t. binocularis and S. t. mikeprestoni. Geographically, the nearest localities for $S$. t. binocularis and S. t. mikeprestoni are separated by $\sim 30 \mathrm{~km}$ airline and $\sim 1600 \mathrm{~m}$ in elevation.

The modeled HSA (Fig. 7) indicates that climatic conditions have been favorable for the $S$. torquatus complex repeatedly in east-central Mexico, as far east as Veracruz, very close to the Gulf of Mexico slope. We did not find populations of $S$. torquatus beyond eastern Tlaxcala during field work, and the historical records from Veracruz that we examined were redetermined as S. mucronatus and S. formosus. According to the HSA, future sampling in western Mexico, along the Sierra Madre Occidental could reveal the discovery of new species of Sceloporus related to the $S$. torquatus complex, as was the case of Sceloporus spp. from Nayarit, Jalisco and Zacatecas.

Although the niche similarity test that we performed is not conclusive (Table 5), we note the fact that four main biogeographic provinces constitute the current geographic distribution of the $S$. torquatus complex, implying a great heterogeneity of suitable habitats and topography. The distribution of some lineages within the $S$. torquatus complex are isolated in mountainous areas where the climatic change has been accelerated (Sinervo et al. 2010), thus future studies could be directed to reassess the extinction risk of these lineages.

It has been suggested that morphological convergence may be related to environmental similarity in other species of the torquatus group (Martínez-Méndez et al. 2012). In the case of the $S$. torquatus complex, we observed morphological conservatism (Figs 8-9) despite their wide geographic distributions (Fig. 1) and heterogeneity of environments inhabited (Table 5). This is clearly observed in $S$. $t$. torquatus which is distributed in central Mexico, where it inhabits mainly pine forests, oak forests and scrub, at $1300-3533 \mathrm{~m}$, and S. t. melanogaster which is distributed throughout central and much of northern Mexico, living mainly in different types of scrub, pine forests, oak forests and grasslands, at 1100-2745m. Both are found frequently on stone walls or fences, in agricultural land, and urban areas. The lack of considerable differences in morphometry and scutellation among the populations of the compared lineages may be a consequence of the relatively recent diversification of the $S$. torquatus complex. In live and preserved specimens, coloration characteristics are generally useful for distinguishing between members of the $S$. torquatus complex, except for specimens from the wide contact zone between $S$. $t$. torquatus and $S$. t. melanogaster along the Faja Volcánica Transmexicana.

As we expected due to its inherent properties, the mtDNA showed higher genetic differentiation than the nDNA and largely drove the phylogeographic patterns discussed above. While we acknowledge the limitations of using solely or mainly mtDNA for species delimitation (Leaché and Mulcahy 2007; Leaché 2010), this practice is commonly used to discern recently diverged lineages such as those comprising species complexes, even within Sceloporus (Wiens and Penkrot 2002; Martínez-Méndez et al. 2012; Díaz-Cárdenas et al. 2017), that would otherwise be difficult to resolve with nDNA alone. The inclusion of genome-wide nuclear markers, such as those generated from next-generation sequencing technology, would add further phylogenetic and taxonomic resolution to this group. 


\section{Conclusions}

With all available evidence examined herein, we conclude that $S$. torquatus represents a multi-faceted taxonomic problem. We identified several different taxa in the syntype series of $S$. torquatus, and discovered a greater diversity than currently recognized within the complex that is masked by recently diverged cryptic species.

For nomenclature to reflect the phylogenetic relationships in the $S$. torquatus complex, we recommend the following taxonomic changes: the reassignment of $S . t$. melanogaster $(=S$. melanogaster $)$ and $S . t$. binocularis $(=S$. binocularis $)$ to species level, and the use of the new combinations S. mikeprestoni comb. nov. and S. madrensis comb. nov. These changes allow $S$. torquatus to be monotypic.

Those populations from southern San Luis Potosí, northeastern Querétaro and northern Hidalgo represent a distinct species that has previously been confused with both S. t. torquatus and S. t. madrensis. Similarly, populations from eastern Zacatecas, previously considered as S. t. melanogaster, represent another unnamed species. Formal descriptions for both will be published separately, including expanded sampling in northern, western, and central Mexico to investigate phylogeographic structure and gene flow between neighboring species (FloresVillela et al. in prep.).

\section{Acknowledgements}

To curators and curatorial staff for data and photographs of the specimens under their custody: David A. Kizirian, Lauren Vonnahme (American Museum of Natural History, AMNH), Ned Gilmore (Academy of Natural Sciences of Philadelphia, ANSP), Alison Whiting (Brigham Young University, BYU), Lauren Scheinberg, Erica Ely (California Academy of Sciences, CAS), Uriel Hernández Salinas (Centro Interdisciplinario de Investigación para el Desarrollo Integral Regional, Unidad Durango, CRD), Stephen Rogers, Stevie Kennedy-Gold (Carnegie Museum of Natural History, CM), Víctor Hugo Reynoso Rosales, Omar Hernández Ordoñez (Colección Nacional de Anfibios y Reptiles, CNAR), Juan Carlos López Vidal†, Cynthia Elizalde Arellano (Escuela Nacional de Ciencias Biológicas, ENCB), Alan Resetar, Joshua Mata (Field Museum of Natural History, FMNH), Max Alan Nickerson, Coleman M. Sheehy (Florida Museum of Natural History, FLMNH), Rafe Brown, Melissa Mayhew, Ana Paula Motta Vieira (Kansas University, KU), Leticia Ochoa Ochoa, Adrián Nieto Montes de Oca (Museo de Zoología Alfonso L. Herrera, MZFC), Frank Tillack (Museum für Naturkunde Berlin, ZMB); James Hanken, Jose Rosado, Joseph Martinez (Museum of Comparative Zoology, MCZ), David Marques (Naturhistorisches Museum Basel, NMB), Toby Hibbitts (Texas Cooperative Wildlife Collection, TCWC), Texas Natural History Collection, TNHC), David Lazcano Villareal (Universidad Autónoma de Nuevo León, UANL); James Poindexter, Addison Wynn, (United States National Museum, USNM), Chris Phillips, Daniel Brian Wylie (University of Illinois Museum of Natural History, UIMNH). To Irene Goyenechea Mayer, Daniel Piñero, Livia S. León, Marisol Motellano, Andrés García, Lázaro Guevara, Carlos Pedraza, Israel Solano, Luis F. Vázquez, Ricardo Palacios, Ricardo Rivera, Gonzalo Medina, Rufino Santos, Luis Canseco, Atziri A. Ibarra, Carlos
A. Hernández, Mauricio Tepos, Sol de Mayo Mejénez, Sergio Terán, Alfredo Sánchez, María L. Ochoa for their invaluable assistance in carying out this work. To the Secretaría del Medio Ambiente y Recursos Naturales (SEMARNAT) for issuing collecting permits to OFV FAUT-0015, and LMOO FAUT-0317. To the staff of Rancho del Cielo and El Cielo Biosphere reserve, Jean L. Lacaille and Martha López. To the staff of Laboratorio Nacional de Biodiversidad (LaNaBio) Laura M. Márquez and Nelly M. López. To the UNAM Postgraduate Program (Posgrado en Ciencias Biológicas). To grant no. PAPIIT-IN216218, from UNAM. To first author, this work constitutes a requirement for obtaining the degree of Master in Biological Sciences of the Posgrado en Ciencias Biológicas, Sistemática, UNAM. GCG and BOB were supported by a CONACYT fellowship (CVU 856512 and 929090, respectively). JAVV was supported by a postdoctoral fellowship from DGAPA-UNAM.

\section{References}

Allouche O, Tsoar A, Kadmon R (2006) Assessing the accuracy of species distribution models: prevalence, kappa and the true skill statistic (TSS). Journal of Applied Ecology 43: 1223-1232.

Baird SF (1859) Reptiles of the boundary, with notes by the naturalists of the survey. Report of the United States and Mexican Boundary Survey. W. H. Emory. 3(2): 1-35, plates 1-41.

Baird SF, Girard C (1852) Characteristics of some new reptiles in the Museum of the Smithsonian Institution, part 2. Proceedings of the Academy of Natural Science of Philadelphia 6: 125-129.

Bell EL, Smith HM, Chiszar D (2003) An annotated list of species-group names applied to the lizard genus Sceloporus. Acta Zoológica Mexicana (n.s.) 90:103-174.

Bouckaert RR, Drummond AJ (2017) bModelTest: Bayesian phylogenetic site model averaging and model comparison. BMC Evolutionary Biology 17(42): 1-11. https://doi.org/10.1186/s12862-0170890-6

Bouckaert R, Vaughan TG, Barido-Sottani J, Duchêne S, Fourment M, Gavryushkina A, Heled J, Jones G, Kühnet D, De Maio N, Matschiner M, Mendes FK, Müller NF, Oglivie HA, du Plessis L, Popinga A, Rambaut A, Rasmussen D, Siveroni I, Suchard MA, Wu C, Xie D, Zhang C, Stadler T, Drummond A (2019) BEAST 2.5: An advanced software platform for Bayesian evolutionary analysis. PLoS Computational Biology 15(4): 28. https://doi.org/10.1371/journal. pcbi. 1006650

Boulenger GA (1885) Catalogue of the lizards in the British Museum (Natural History) 2nd. Edition. Vol. 2. Taylor and Francis, London, 497 pp.

Boulenger GA (1895) Second report on additions to the lizard collection in the Natural History Museum. Proceedings of the Zoological Society of London 1894: 722-736.

Broennimann O, Fitzpatrick MC, Pearman PB, Petitpierre B, Pellissier L, Yoccoz NG, Thuiller W, Fortin MJ, Randin C, Zimmermann NE, Graham CH, Guisan A (2012). Measuring ecological niche overlap from occurrence and spatial environmental data. Global Ecology and Biogeography 21: 481-497.

Brown JL, Hill DJ, Dolan AM, Carnaval AC, Haywood AM (2018) Paleoclim, high spatial resolution paleoclimate surfaces for global land areas. Scientific Data 5: 1-9.

Bryson jr. RW, García-Vázquez UO, Riddle BR (2012) Relative roles of Neogene vicariance of bunchgrass lizards (Sceloporus scalaris group) in Mexico. Molecular Phylogenetics and Evolution 62: 447457. https://doi.org/10.1016/j.ympev.2011.10.01 
Bryson jr. RW, Murphy RW, Graham MR, Lathrop A, Lazcano D (2011) Ephemeral Pleistocene woodlands connect the dots for highland rattlesnakes of the Crotalus intermedius group. Journal of Biogeography 38(12): 2299-2310. https://doi.org/10.1111/j.1365-2699.2011.02565.x

Cope ED (1866) Fourth contribution to the herpetology of tropical America. Proceedings of the American Philosophical Society 18: $123-132$.

Cope ED (1885) A contribution to the herpetology of Mexico. Proceedings of the American Philosophical Society 228(120) Part IV: 379-404.

Di Cola V, Broennimann O, Petitpierre B, Breiner FT, D'Amen M, Randin C, Engler R, Pottier J, Pio D, Dubuis A, Pellissier L, Mateo RG, Hordjk W, Salamin N, Guisan A (2017) ecospat: an R package to support spatial analyses and modeling of species niches and distributions. Ecography 40: 774-787.

Díaz-Cárdenas B, Ruiz-Sanchez E, Castro-Felix P, Castañeda-Gaytán G, Ruiz-Santana S, Gadsden H (2017) Species delimitation of the blue-spotted spiny lizards within a multilocus, multispecies coalescent framework, results in the recognition of a new Sceloporus species. Molecular Phylogenetics and Evolution 111: 185-195. https:// dx.doi.org/10.1016/j.ympev.2017.04.00

Díaz-Cárdenas B, Ruiz-Sanchez E, Gadsden H, García-Enriquez JM, Castro-Felix P, Castañeda-Gaytán G, Santerre A (2019) Physiographic and climatic events in the Chihuahuan Desert led to the speciation and distinct demographic patterns of two sister Sceloporus lizards. Journal of Zoological Systematics and Evolutionary Research 2019: 1-13. https://doi:10.1111/jzs.12296

Dugès A (1887) Erpetología del Valle de Mexico. La Naturaleza segunda serie 1: 97-146.

Dunn ER (1936) The amphibians and reptiles of the Mexican Expedition of 1934. Proceedings of the Academy of Natural Sciences of Philadelphia 88: 471-477.

Edgar RC (2004) MUSCLE: multiple sequence alignment with high accuracy and high throughput. Nucleic Acids Research 32(5): 19721797.

Feria Ortiz M, Nieto-Montes De Oca A, Salgado Ugarte IH (2001) Diet and reproductive biology of the viviparous lizard Sceloporus torquatus torquatus (Squamata: Phrynosomatidae). Journal of Herpetology 35(1): 104-112.

Fielding AH, Bell JF (1997) A review of methods for the assessment of prediction errors in conservation presence/absence models. Environmental Conservation 24: 38-49.

Flores-Villela O, García-Vázquez UO (2014) Biodiversidad de reptiles en México. Revista Mexicana de Biodiversidad, Supl. 85: S467-S475.

Forstner MR, Davis SK, Arévalo E (1995). Support for the hypothesis of anguimorph ancestry for the suborder Serpentes from phylogenetic analysis of mitochondrial DNA sequences. Molecular Phylogenetics and Evolution 4(1): 93-102.

Grummer J, Calderón-Espinosa ML, Nieto-Montes de Oca A, Smith EN, Méndez-De la Cruz FR, Leaché AD (2015) Estimating the temporal and spatial extent of gene flow among sympatric lizard populations (genus Sceloporus) in the southern Mexican highlands. Molecular Ecology 24: 1523-1542. https://doi.org/10.1111/mec.13122

Guillette Jr. LJ, Méndez-De la Cruz F (1993) The reproductive cycle of the viviparous Mexican lizard Sceloporus torquatus. Journal of Herpetology 27(2): 168-174.

Hammer Ø, Harper, DAT, Ryan PD (2001) PAST: Paleontological Statistics software package for education and data analysis. Paleontologica Electronica 4(1): 1-9.
Hunsaker II D (1962) Ethological isolating mechanisms in the Sceloporus torquatus group of lizards. Evolution 16(1): 62-74.

ICZN [International Commission on Zoological Nomenclature] (1999) International code of zoological nomenclature. Fourth Edition. The International Trust for Zoological Nomenclature, London.

Jiménez-Arcos VH, Sanabria-Urbán S, Cueva del Castillo R (2017) The interplay between natural and sexual selection in the evolution of sexual size dimorphism in Sceloporus lizards (Squamata: Phrynosomatidae). Ecology and Evolution 7: 905-917. https://doi. org/10.1002/ece3.2572

Kimura M (1980) A simple method for estimating evolutionary rates of base substitutions through comparative studies of nucleotide sequences. Journal of Molecular Evolution 16: 111-120.

Kocher TD, Thomas WK, Meyer A, Edwards SV, Pääbo S, Villablanca FX, Wilson AC (1989) Dynamics of mitochondrial DNA evolution in animals: Amplification and sequencing with conserved primers. Proceedings of the National Academy of Science 86: 6196-6200.

Köhler G, Heimes P (2002) Stachelleguane. Herpeton, Frankfurt am Main, 174 pp.

Kumar S, Stecher G, Li M, Knyaz C, Tamura K (2018) MEGA X: Molecular Evolutionary Genetics Analysis across computing platforms. Molecular Biology and Evolution 35: 1547-1549.

Lambert SM, Streicher JW, Fischer-Reid MC, Méndez de la Cruz FR, Martínez-Méndez N, García-Vázquez UO, Nieto Montes de Oca A, Wiens JJ (2019) Inferring introgression using RADseq and $D_{\text {FOIL }}$ : Power and pitfalls revealed in a case study of spiny lizards (Sceloporus). Molecular Ecology Resources 818-837. https://doi. org/10.1111/1755-0998.12972

Lanfear R, Frandsen PB, Wright AM, Senfeld T, Calcott B (2016) Partition Finder 2: New methods for selecting partitioned models of evolution for molecular and morphological phylogenetic analyses. Molecular Biology and Evolution 1-2. https://doi.org/10.1093/molbev/msw260

Leaché AD (2010) Species trees for spiny lizards (Genus: Sceloporus): identifying points of concordance and conflict between nuclear and mitochondrial data. Molecular Phylogenetics and Evolution 54: $162-171$.

Leaché AD, Mulcahy DG (2007) Phylogeny, divergence times and species limits of spiny lizards (Sceloporus magister species group) in western North American deserts and Baja California. Molecular Ecology 16: 5216-5233.

Leaché AD, Reeder TW (2002) Molecular systematics of the easter fence lizard (Sceloporus undulatus): A comparison of parsimony, likelihood, and bayesian approaches. Systematic Biology 51(1): 44-68.

Leaché AD, Banbury BL, Linkem CW, Nieto-Montes de Oca A (2016) Phylogenomics of a rapid radiation: is chromosomal evolution linked to increased diversification in North American spiny lizards (Genus Sceloporus)?. BMC Evolutionary Biology 16(63): 1-16.

Leaché AD, Palacios JA, Minin VN, Bryson Jr. RW (2013) Phylogeography of the Trans-Volcanic bunchgrass lizard (Sceloporus bicanthalis) across the highlands of south-eastern Mexico. Biological Journal of the Linnean Society 110: 852-865.

Marquaridt DW (1970) Generalized inverses, ridge regression, biased linear estimation, and nonlinear estimation. Technometrics, 12(3): 591-612.

Martin PS (1952) A new subspecies of the iguanid lizard Sceloporus serrifer from Tamaulipas. Occasional Papers of the Museum of Zoology, University of Michigan 543: 1-7. 
Martínez-Méndez N, Méndez-De la Cruz FR (2007) Molecular phylogeny of the Sceloporus torquatus species-group (Squamata: Phrynosomatidae). Zootaxa 1609: 53-68.

Martínez-Méndez N, Mejía O, Ortega J, Méndez-De la Cruz F (2019) Climatic niche evolution in the viviparous Sceloporus torquatus group (Squamata: Phrynosomatidae). PeerJ 6:e6192. https://doi. org $/ 10.7717 /$ peerj. 6192

Martínez-Méndez, N, Mejía O, Rocha-Gómez A, Méndez-De la Cruz FR (2012) Morphological convergence and molecular divergence: the taxonomic status of Sceloporus serrifer (Squamata, Phrynosomatidae) subspecies. Zoologica Scripta 41(2): 97-108.

Miller MA, Pfeiffer W, Schwartz T (2010) Creating the CIPRES Science Gateway for inference of large phylogenetic trees. New Orleans LA, November 2010. Proceedings of the Gateway Computing Environments Workshop (GCE), 1-8.

Morafka M (1977) A biogeographical analysis of the Chihuahuan Desert through its herpetofauna. Biogeographica. Dr. W. Junk B. V. Publishers, The Hague, $313 \mathrm{pp}$.

Naimi B, Araújo MB (2016) sdm: a reproducible and extensible R platform for species distribution modelling. Ecography 39(4): 368-375.

Naimi B, Hamm NA, Groen TA, Skidmore AK, Toxopeus AG (2014) Where is positional uncertainty a problem for species distribution modelling? Ecography 37: 191-203.

Olson RE (1986) A new subspecies of Sceloporus torquatus from the Sierra Madre Oriental, Mexico. Bulletin of the Maryland Herpetological Society 22(3): 167-170.

Olson RE (1990) Sceloporus torquatus: Its variation and zoogeography. Bulletin of the Chicago Herpetological Society 25(7): 117-127.

Olson RE (1991) Sceloporus torquatus madrensis in San Luis Potosi Mexico. Bulletin of the Maryland Herpetological Society 27(1): 38-39.

Peale TR, Green J (1829) Description of two new species of the Linnean genus Lacerta. Journal of the Academy of Natural Sciences of Philadelphia 6(1): 231-234.

Rambaut A (2018) FigTree, Tree Figure Drawing Tool, Version 1.4.4 https://github.com/rambaut/figtree/releases

Rambaut A, Drummond AJ, Xie D, Baele G, Suchard MA (2018) Posterior summarization in Bayesian phylogenetics using Tracer 1.7. Systematic Biology 67(5): 901-904.

Ronquist F, Teslenko M, van der Mark P, Ayres DL, Darling A, Höhna S, Larget B, Liu L, Suchard MA, Huelsenbeck JP (2012) MRBAYES 3.2: Efficient Bayesian phylogenetic inference and model selection across a large model space. Systematic Biology 61: 539-542.

Sinervo B, Méndez-de La Cruz F, Miles DB, Heulin B, Bastiaans E, Villagrán-Santa Cruz M, Lara-Resendiz R, Martínez-Méndez N, Calderón-Espinosa ML, Meza-Lázaro RN, Gadsden H, Avila LJ, Morando M, De la Riva IJ, Sepulveda PV, Rocha CFD, Ibargüengoytía N, Puntriano CA, Massot M, Lepetz V, Oksanen TA, Chapple DG, Bauer AM, Branch WR, Clobert J, Sites Jr. JW (2010) Erosion of Lizard Diversity by Climate Change and Altered Thermal Niches. Science 328, 894-899. https://doi.org/10.1126/science.1184695

Sites Jr. JW, Archie JW, Cole CJ, Flores Villela O (1992) A review of phylogenetic hypotheses for lizards of the genus Sceloporus (Phrynosomatidae): implications for ecological and evolutionary studies. Bulletin of the American Museum of Natural History 213, $1-110$.

Smith HM (1936) Descriptions of new species of lizards of the genus Sceloporus from Mexico. Proceedings of the Biological Society of Washington 49: 87-96.
Smith HM (1938) The lizards of the torquatus group of the genus Sceloporus Wiegmann, 1828. The University of Kansas Science Bulletin 24(21): 539-693 (1936).

Smith HM (1939) The Mexican and Central American lizards of the genus Sceloporus. Zoological Series, Field Museum of Natural History 26: 1-397.

Smith HM (1942) Mexican herpetological miscellany. Proceedings of the United States National Museum 92(3153): 349-395.

Smith HM, Álvarez T (1974) Possible intraspecific sympatry in the lizard species Sceloporus torquatus, and its relationships with S. cyanogenys. Transactions of the Kansas Academy of Science 77(4): 219-224.

Smith HM, Taylor EH (1950) An annotated checklist and key to the reptiles of Mexico exclusive of the snakes. Bulletin of the United States National Museum 199: 1-253.

Soberón J, Peterson AT (2005) Interpretation of models of fundamental ecological niches and species' distributional areas. Biodiversity Informatics 2: 1-10.

Stamatakis A (2014) RAxML version 8: a tool for phylogenetic analysis and post-analysis of large phylogenies. Bioinformatics 30(9): $1312-1313$.

Taylor EH (1969) Wiegmann and the herpetology of México. In Wiegmannn, A. F. A. Herpetologia mexicana. Facsimile reprint by the Society for the Study of Amphibians and Reptiles (23): i-iv, 1-54.

Thornalley DJ, Elderfield RH, McCave IN (2010) Intermediate and deep water paleoceanography of the northern North Atlantic over the past 21,000 years. Paleoceanography 25, PA1211. https://doi. org/10.1029/2009PA001833

Thornalley DJ, Barker RS, Broecker WS, Elderfield H, McCave IN (2011) The deglacial evolution of North Atlantic deep convection. Science 331: 202-205.

Thornalley DJ, Blascheck RM, Davies FJ, Praetorius SK, Oppo DW, McManus JF, Hall IR, Kleiven H, Renssen H, McCave IN (2013) Long-term variations in Iceland- Scotland overflow strength during the Holocene. Climate of the Past 9: 2073-2084.

Uetz P, Freed P, Hošek J (2020) The Reptile Database http://www.reptile-database.org

Velasco JA, Herrel A (2007) Ecomorphology of Anolis lizards of the Choco' region in Colombia and comparisons with Greater Antillean ecomorphs. Biological Journal of the Linnean Society 92: 29-39.

Webb RG (1967) Variation and distribution of the iguanid lizard Sceloporus bulleri, and the description of a related new species. Copeia 1967: 202-213.

Wied-Neuwied MP zu (1820) Reise nach Brasilien in den Jahren 1815 bis 1817. Vol. 1. Heinrich Ludwig Brönner, Frankfurt am Main, $454 \mathrm{pp}$.

Wiegmann AFA (1828) Beyträge zur Amphibienkunde. Isis von Oken 21(3-4): 364-384.

Wiegmann AFA (1834) Herpetologia Mexicana seu descriptio amphibiorum Novae Hispaniae. Pars prima. Saurorum species. Lüderitz, Berlin, 253 pp.

Wiens JJ, Penkrot TA (2002) Delimiting species using DNA and morphological variation and discordant limits in Spiny Lizards (Sceloporus). Systematic Biology 51(1): 69-91.

Wiens JJ, Kuczynski CA, Arif S, Reeder TW (2010) Phylogenetics relationships of phrynosomatid lizards based on nuclear and mitochondrial data, and a revised phylogeny for Sceloporus. Molecular Phylogenetics and Evolution 54: 150-161. 
Wiens JJ, Kozak H, Silva N (2013) Diversity and niche evolution along aridity gradients in North American lizards (Phrynosomatidae). Evolution 67(6): 1-14. https://doi.org/10.1111/evo.12053
Yarrow HC (1882) Checklist of North American Reptilia and Batrachia with catalogue of specimens in the U. S. National Museum. Bulletin of the United States National Museum 30(24): 1-249.

\section{Supplementary material 1}

\section{Specimens and localities}

Authors: Campillo-García G, Flores-Villela O, Butler BO, Velasco Vinasco JA, Ramírez Corona F (2021)

Data type: .docx

Explanation note: Museum specimens and localities.

Copyright notice: This dataset is made available under the Open Database License (http://opendatacommons.org/licenses/odbl/1.0). The Open Database License (ODbL) is a license agreement intended to allow users to freely share, modify, and use this Dataset while maintaining this same freedom for others, provided that the original source and author(s) are credited.

Link: https://doi.org/10.3897/vz.71.e71995.suppl1

\section{Supplementary material 2}

\section{Specimen vouchers}

Authors: Campillo-García G, Flores-Villela O, Butler BO, Velasco Vinasco JA, Ramírez Corona F (2021)

Data type: .xlsx

Explanation note: Specimen vouchers and genetic sequences.

Copyright notice: This dataset is made available under the Open Database License (http://opendatacommons.org/licenses/odbl/1.0). The Open Database License (ODbL) is a license agreement intended to allow users to freely share, modify, and use this Dataset while maintaining this same freedom for others, provided that the original source and author(s) are credited.

Link: https://doi.org/10.3897/vz.71.e71995.supp12

\section{Supplementary material 3}

\section{Morphometric measurements}

Authors: Campillo-García G, Flores-Villela O, Butler BO, Velasco Vinasco JA, Ramírez Corona F (2021)

Data type: .xlsx

Explanation note: Morphometric measurements.

Copyright notice: This dataset is made available under the Open Database License (http://opendatacommons.org/licenses/odbl/1.0). The Open Database License (ODbL) is a license agreement intended to allow users to freely share, modify, and use this Dataset while maintaining this same freedom for others, provided that the original source and author(s) are credited.

Link: https://doi.org/10.3897/vz.71.e71995.suppl3 


\section{Supplementary material 4}

\section{Scalation counts}

Authors: Campillo-García G, Flores-Villela O, Butler BO, Velasco Vinasco JA, Ramírez Corona F (2021)

Data type: .xlsx

Explanation note: Scalation counts.

Copyright notice: This dataset is made available under the Open Database License (http://opendatacommons.org/licenses/odbl/1.0). The Open Database License (ODbL) is a license agreement intended to allow users to freely share, modify, and use this Dataset while maintaining this same freedom for others, provided that the original source and author(s) are credited.

Link: https://doi.org/10.3897/vz.71.e71995.suppl4

\section{Supplementary material 5}

\section{Statistics}

Authors: Campillo-García G, Flores-Villela O, Butler BO, Velasco Vinasco JA, Ramírez Corona F (2021)

Data type: .docx

Explanation note: Morphometric and scalation statistics.

Copyright notice: This dataset is made available under the Open Database License (http://opendatacommons.org/licenses/odbl/1.0). The Open Database License (ODbL) is a license agreement intended to allow users to freely share, modify, and use this Dataset while maintaining this same freedom for others, provided that the original source and author(s) are credited.

Link: https://doi.org/10.3897/vz.71.e71995.supp15

\section{Supplementary material 6}

\section{Morphometric statistics}

Authors: Campillo-García G, Flores-Villela O, Butler BO, Velasco Vinasco JA, Ramírez Corona F (2021)

Data type: .xlsx

Explanation note: Morphometric statistics.

Copyright notice: This dataset is made available under the Open Database License (http://opendatacommons.org/licenses/odbl/1.0). The Open Database License (ODbL) is a license agreement intended to allow users to freely share, modify, and use this Dataset while maintaining this same freedom for others, provided that the original source and author(s) are credited.

Link: https://doi.org/10.3897/vz.71.e71995.supp16 